\title{
Identification of Key MicroRNAs and the Underlying Molecular Mechanism in Spinal Cord Ischemia-Reperfusion Injury in rats
}

\author{
Fengshou Chen ${ }^{1}$, Jie Han ${ }^{1}$, Dan Wang ${ }^{\text {Corresp. } 1}$ \\ ${ }^{1}$ Department of Anesthesiology, the First Hospital of China Medical University, Shenyang, Liaoning province, China, Shenyang, Liaoning Province, China \\ Corresponding Author: Dan Wang \\ Email address: wonder12251@hotmail.com
}

Spinal cord ischemia-reperfusion injury (SCII) is a pathological process with severe complications such as paraplegia and paralysis. Aberrant miRNA expression is involved in the development of SCII. Differences in the experimenters, filtering conditions, control selection, and sequencing platform may lead to different miRNA expression results. This study systematically analyzes the available SCII miRNA expression data to explore the key differently expressed miRNAs (DEmiRNAs) and the underlying molecular mechanism in SCII. A systematic bioinformatics analysis was performed on 23 representative rat SCII miRNA datasets from PubMed. The target genes of key DEmiRNAs were predicted on miRDB. The DAVID and TFactS databases were utilized for functional enrichment and transcription factor binding analyses. In this study, 19 key DEmiRNAs involved in SCII were identified, 9 of which were upregulated (miR-144-3p, miR-3568, miR-204, miR-30c, miR-34c-3p, miR-155-3p, miR-200b, miR-463, and miR-760-5p) and 10 downregulated (miR-28-5p, miR-21-5p, miR-702-3p, miR-291a-3p, miR-199a-3p, miR-352, miR-743b-3p, miR-125b-2-3p, miR-129-1-3p, and miR-136). KEGG enrichment analysis on the target genes of the upregulated DEmiRNAs revealed that the involved pathways were mainly CGMP-PKG and CAMP signaling pathway. KEGG enrichment analysis on the target genes of the downregulated DEmiRNAs revealed that the involved pathways were mainly Chemokine and MAPK signaling pathway. GO enrichment analysis indicated that the target genes of the upregulated DEmiRNAs were markedly enriched in biological processes such as brain development and the positive regulation of transcription from RNA polymerase II promoter. Target genes of the downregulated DEmiRNAs were mainly enriched in biological processes such as intracellular signal transduction and negative regulation of cell proliferation. According to the transcription factor analysis, the 4 transcription factors, including SP1, GLI1, GLI2, and FOXO3, had important regulatory effects on the target genes of the key DEmiRNAs. Among the upregulated DEmiRNAs, miR-3568 was especially interesting. While SCII causes severe neurological deficits of lower extremities, the antimiRNA oligonucleotides (AMOs) of miR-3568 improve neurological function. Cleaved Peer] reviewing PDF | (2020:11:55270:2:0:NEW 18 Apr 2021) 
caspase-3 and Bax was markedly upregulated in SCII comparing to the sham group, and miR-3568 AMO reduced the upregulation. $\mathrm{BCl}-2$ expression levels showed a opposite trend as cleaved caspase-3. The expression of GATA6, GATA4, and RBPJ decreased after SCII and miR-3568 AMO attenuated this upregulation. In conclusion, 19 significant DEmiRNAs in the pathogenesis of SCIl were identified, and the underlying molecular mechanisms were validated. The DEmiRNAs could serve as potential intervention targets for SCll. Moreover, inhibition of miR-3568 preserved hind limb function after SCII by reducing apoptosis, possibly through regulating GATA6, GATA4, and RBPJ in SCII. 
4 Department of Anesthesiology, the First Hospital of China Medical University, Shenyang,

5 Liaoning province, China

6 Authors:

7 1) Fengshou Chen

8 Address: Department of Anesthesiology, the First Hospital of China

\section{Identification of Key MicroRNAs and the Underlying Molecular Mechanism in Spinal Cord Ischemia-Reperfusion Injury in rats}

Fengshou Chen, Jie Han, Dan Wang

Medical University, Shenyang, Liaoning province, China.

Email: haoxiu19881988@126.com

Tel: +862483283100

Conflicts: Fengshou Chen reported no conflicts of interest.

2) Jie Han

Address: Department of Anesthesiology, the First Hospital of China Medical University, Shenyang, Liaoning province, China.

Email:470452743@qq.com

Tel: +862483283100

Conflicts: Jie Han reported no conflicts of interest.

3) Dan Wang

Address: Department of Anesthesiology, the First Hospital of China Medical University, Shenyang, Liaoning province, China.

Email: wonder12251@hotmail.com

Tel: +862483283100

Conflicts: Dan Wang reported no conflicts of interest.

Corresponding author: Dan Wang

Address: No. 155 Nangjing North Street, Shenyang, Liaoning Province, China.

Email: wonder12251@hotmail.com 
Tel: +862483283100

\section{Abstract}

Spinal cord ischemia-reperfusion injury (SCII) is a pathological process with severe complications such as paraplegia and paralysis. Aberrant miRNA expression is involved in the development of SCII. Differences in the experimenters, filtering conditions, control selection, and sequencing platform may lead to different miRNA expression results. This study systematically analyzes the available SCII miRNA expression data to explore the key differently expressed miRNAs (DEmiRNAs) and the underlying molecular mechanism in SCII. A systematic bioinformatics analysis was performed on 23 representative rat SCII miRNA datasets from PubMed. The target genes of key DEmiRNAs were predicted on miRDB. The DAVID and TFactS databases were utilized for functional enrichment and transcription factor binding analyses. In this study, 19 key DEmiRNAs involved in SCII were identified, 9 of which were upregulated (miR-144-3p, miR-3568, miR-204, miR-30c, miR-34c-3p, miR-155-3p, miR-200b, miR-463, and miR-760-5p) and 10 downregulated (miR-28-5p, miR-21-5p, miR-702-3p, miR291a-3p, miR-199a-3p, miR-352, miR-743b-3p, miR-125b-2-3p, miR-129-1-3p, and miR-136). KEGG enrichment analysis on the target genes of the upregulated DEmiRNAs revealed that the involved pathways were mainly cGMP-PKG and cAMP signaling pathway. KEGG enrichment analysis on the target genes of the downregulated DEmiRNAs revealed that the involved pathways were mainly Chemokine and MAPK signaling pathway. GO enrichment analysis indicated that the target genes of the upregulated DEmiRNAs were markedly enriched in biological processes such as brain development and the positive regulation of transcription from RNA polymerase II promoter. Target genes of the downregulated DEmiRNAs were mainly enriched in biological processes such as intracellular signal transduction and negative regulation of cell proliferation. According to the transcription factor analysis, the 4 transcription factors, including SP1, GLI1, GLI2, and FOXO3, had important regulatory effects on the target genes of the key DEmiRNAs. Among the upregulated DEmiRNAs, miR-3568 was especially interesting. 
55

While SCII causes severe neurological deficits of lower extremities, the anti-miRNA oligonucleotides (AMOs) of miR-3568 improve neurological function. Cleaved caspase-3 and Bax was markedly upregulated in SCII comparing to the sham group, and miR-3568 AMO reduced the upregulation. Bcl-2 expression levels showed a opposite trend as cleaved caspase-3. The expression of GATA6, GATA4, and RBPJ decreased after SCII and miR-3568 AMO attenuated this upregulation. In conclusion, 19 significant DEmiRNAs in the pathogenesis of SCII were identified, and the underlying molecular mechanisms were validated. The DEmiRNAs could serve as potential intervention targets for SCII. Moreover, inhibition of miR-3568 preserved hind limb function after SCII by reducing apoptosis, possibly through regulating GATA6, GATA4, and RBPJ in SCII.

Keywords: microRNA; spinal cord ischemia-reperfusion injury; bioinformatics analysis; transcription factor analysis

\section{Introduction}

Spinal cord ischemia-reperfusion injury (SCII) is the damage caused by the restoration of blood perfusion in the ischemic spinal cord tissues (Fang et al. 2015). The normal function of the spinal cord may be hindered by SCII, resulting in severe complications such as paraplegia and paralysis (Smith et al. 2012). Current drugs and therapeutic measures for SCII are effectual but deficient. Hence, SCII remains a significant challenge in clinical therapy (Xu et al. 2014b). It is necessary to identify new molecular targets for SCII.

MicroRNAs (miRNAs) are non-coding RNAs 20 to $22 \mathrm{nt}$ in length that regulate target genes expression at the post-transcriptional level via base-pairing with the 3'-untranslated region (3'UTR) of mRNA (Balsam 2017; Zhai et al. 2012). Due to the involvement in the numerous biological processes, such as neurogenesis, inflammation, apoptosis, and autophagy, miRNAs may conduce to the pathogenesis of the central nervous system (CNS) disorders, including SCII, cerebral ischemia-reperfusion injury (CIRI), spinal cord injury (SCI), and Parkinson's disease (Bhalala et al. 2013; Li et al. 2018a; Li et al. 2018b; Wang et al. 2020b). Moreover, aberrant 
81 miRNAs expression has been connected to the development of SCII at different stages (Hu et al.

82 2013; Li et al. 2016a; Liu et al. 2020).

83 This study aims to furnish the authentic miRNA data and predict the target genes linked with the

84 occurrence and development of SCII. The role of the contrastingly expressed miRNAs in regulating the target genes during SCII and the altered miRNA-TF regulatory patterns were established based on the TFactS database (http://www.tfacts.org/) to provide significant clues for targeting the key miRNAs as molecular markers in the treatment of SCII. The involvement of selected miRNA and its target genes in SCII were also verified.

\section{Material and Methods}

\section{Identification of the key differentially expressed miRNAs in SCII}

The existing studies on the miRNA expressions in SCII were located on PubMed with keywords such as miRNA and spinal cord ischemic reperfusion injury on Nov. 30, 2020. The species involved in the related studies were limited to rats. The information on SCII and the miRNA sequencing samples and the detection methods for the differentially expressed miRNAs (DEmiRNAs) were extracted from the relevant studies. The upregulated and downregulated DEmiRNAs in SCII compared with the sham groups were also extracted. The DEmiRNAs occurrence of each dataset was calculated, and DEmiRNAs that appeared in at least two datasets were defined as key DEmiRNAs.

\section{Predicting the target genes of DEmiRNAs in SCII}

The target genes of DEmiRNAs were predicted on miDRB with the gene target score set to over 80.

\section{Gene ontology and KEGG enrichment analysis on the target genes of DEmiRNAs in SCII}

Information on the target genes of DEmiRNAs was obtained from the DAVID database for KEGG pathway analysis and GO enrichment analysis (Guo et al. 2019). The cut-off criteria for 
106

107

108

109

110

111

112

113

114

115

116

117

118

119

120

121

122

123

124

125

126

127

128

129

130

131

the Kyoto Encyclopedia of Genes and Genomes (KEGG) pathway enrichment and the gene ontology (GO) term enrichment were statistical significance $(p<0.05)$. According to the relations between the genes and the statistically significant biological processes as well as the relations among miR-3568, genes, and the biological processes, a miR-3568-biological processes-gene network was built.

\section{Transcription factor analysis of the miRNA-regulated target genes in SCII}

The target genes of DEmiRNAs in SCII were submitted to the TFactS database (http://www.tfacts.org/), and the transcription factors regulating the target genes of DEmiRNAs were predicted by the false discovery rate, E value, $q$ value, and $p$ value. To obtain reliable transcription factors, the false discovery rate, E value, $q$ value, and $p$ value should all be lower than 0.05. The transcription factors of the target genes of DEmiRNAs were counted, respectively. The unique and common transcription factors were compared.

\section{Rat model}

Male Sprague Dawley (SD) rats, 8 weeks, weighing 200-250 g, used in the SCII model were purchased from Liaoning Changsheng Biotechnology Co., Ltd. This study was approved by the Ethics Committee of China Medical University (CMU2020266). SCII was induced in the rats via a cross-clamped aortic arch (Li et al. 2014a; Li et al. 2014b). Briefly, upon anesthesia by intraperitoneally injecting 4\% sodium pentobarbital (50 mg/kg; Beyotime Biotechnology, China), endotracheal intubation (24 g trocar sleeve) and lung ventilation was accomplished with a small-animal ventilator (Harvard Apparatus, USA; tidal $15 \mathrm{~mL} / \mathrm{kg}$, breathing frequency 80-100 times/min, breathing ratio $1: 1$ ). Body temperatures were kept at $37.5 \pm 0.5^{\circ} \mathrm{C}$ and monitored with a rectal probe. Under aseptic conditions, the left common carotid artery was exposed in the middle of neck. Then, the aortic arch was uncovered through a cervicothoracic incision. Under direct vision, the aortic arch was cross-clamped for 14 min between the left carotid artery and the left subclavian artery to induce ischemia. A catheter ( $24 \mathrm{~g}$ trocar sleeve) was inserted into the femoral artery for blood pressure measurements. After ischemia confirmation $(90 \%$ reduction of 
132 the flow assessed at the femoral artery using a laser Doppler blood flow monitor (Moor 133 Instruments, Axminster, Devon, UK)), the clamping was removed, followed by 24-hour 134 reperfusion. This procedure was performed on the sham animals, except for blockade.

135

136

137

138

139

140

141

142

\section{Interventions}

Thirty-two male SD rats were assigned randomly to four groups: (1) sham group; (2) SCII group; (3) SCII + anti-miRNA oligonucleotides (AMOs) of miR-3568 group; and (5) SCII + NC-miR3568 group. Rats were intrathecally injected with AMOs (Li et al., 2015b). A synthetic miR-1865p AMO (AMO-3568) (5'-CUGCUUCUGCACGGGAAGAACA-3'), and negative control were purchased from Jima Inc (China). Rats were intrathecally injected with liposome complexes of the oligonucleotides $(50 \mathrm{mg} / \mathrm{kg})$ and Lipofectamine ${ }^{\circledR} 2000$ (Invitrogen, USA). Rats were injected once a day for three consecutive days before the surgical procedure.

\section{Quantitative reverse transcription-polymerase chain reaction (qRT-PCR)}

Rats were euthanized by sevoflurane overdose at $24 \mathrm{~h}$ after SCII in accordance with the established protocol by the Experimental Animal Center of China Medical University. Segments L4-L6 of the spinal cord were collected to extract total RNA with the Trizol reagent (Takara, Otsu, Japan). The RNA was reverse-transcribed into cDNA using a Prime-Script RT reagent Kit with gDNA Eraser (Takara) (Jia et al. 2019). The levels of miRNA were measured using an SYBR Premix qRT-PCR (Takara) on the Applied Biosystems 7500 Real Time PCR system (Takara) with U6 as an internal control. The primer sequences are shown in Table 1 . The $2^{-\Delta \Delta \mathrm{Ct}}$ method was used to calculate the data.

\section{Neurological evaluation}

At $24 \mathrm{~h}$ after SCII, the hind limb functions were evaluated based on the Tarlov scores: $0=$ no voluntary hind limb function, $1=$ poor hind limb motor function with perceptible movement, $2=$ joint motion present with no ability to stand, $3=$ stands and walks, and $4=$ normal hind limb function (Fang et al. 2015; Li et al. 2016b; Tarlov 1972). 
157

\section{Western Blotting}

The expression levels of GATA6, GATA4, RBPJ, BCL-2, Bax, and cleaved caspase-3 in spinal cord tissues were measured with Western Blotting. Total proteins were extracted from the L4-L6 segments of the spinal cords with RIPA buffer (KangChen, China). The antibodies used were rabbit polyclonal anti-GATA6 (Affinity, AF5270, China), rabbit polyclonal anti-GATA4 (Affinity, AF5245, China), rabbit polyclonal anti-RBPJ (Affinity, DF7453, China), rabbit monoclonal anti-Bax (Cell Signaling Technology, \#2772, USA), rabbit polyclonal anti-Bcl-2 (ProteinTech, 26593-1-AP, USA), rabbit polyclonal anti- cleaved caspase-3 (Abcam, ab2302, USA), rabbit anti-GAPDH (Boster, A00227, China), and HRP-conjugated secondary antibodies (Beyotime, China).

\section{Statistical analysis}

SPSS 15.0 (IBM, USA) was used for statistical analyses. The results were expressed as mean \pm standard deviation. Student's t-test, one-way ANOVA followed by the Tukey's test, or two-way repeated-measures ANOVA with the appropriate post hoc analysis were adopted to calculate the significant difference. $p<0.05$ was defined as significant.

\section{Results}

The analysis process is demonstrated in Figure 1. The key DEmiRNAs in SCII were identified first, then the target genes of the DEmiRNAs were predicted, GO and KEGG enrichment analysis and transcription factor analysis were conducted. The occurrence of DEmiRNAs in each of the datasets was calculated, and DEmiRNAs appearing in at least two datasets were identified as key DEmiRNAs. Moreover, qRT-PCR was adopted to measure the expression of the key DEmiRNAs. One of the key DEmiRNAs, miR-3568, was especially interesting; thus, the involvement of miR-3568 in SCII was preliminarily explored.

\section{Searching and identification of key DEmiRNAs in SCII}


181 From the existing SCII miRNA expression profiling in rats, 23 independent miRNA expression

182

183

184

185

186

187

188

189

190

191

192

193

194

195

196

197

198

199

200

201

202

203

204

205

206 datasets were obtained from PubMed, which provided the DEmiRNAs in the spinal cord tissues of SCII rats compared with the sham rats. SCII miRNA datasets were named based on the corresponding authors and year of publication for further study. Basic characteristics of SCII DEmiRNAs datasets were displayed in Table 2.

The number of DEmiRNAs in each of the 23 SCII miRNA expression datasets was different (Figure 2). A total of 151 DEmiRNAs were identified in the 23 SCII miRNA expression datasets. Several studies identified more DEmiRNAs than others, such as HJR2013, LXQ2015, and ZGL2020. The number of DEmiRNAs in dataset ZGL2020 was the largest (12 and 13 upregulated DEmiRNAs; 1 and 27 downregulated DEmiRNAs). Due to the differences in DEmiRNAs among the datasets, a systematic analysis of the SCII miRNA differential expression datasets was conducted to identify the key DEmiRNAs and the related potential biological functions in SCII.

DEmiRNAs appearing in at least two datasets were defined as key DEmiRNAs, and a total of 19 key DEmiRNAs were identified (Figure 2 and 3). SCII induced 9 upregulated expressions, namely, miR-144-3p, miR-3568, miR-204, miR-30c, miR-200b, miR-463, miR-760-5p, miR155-3p, and miR-34c-3p, and 10 downregulated expressions, namely, miR-125b-2-3p, miR-215p, miR-199a-3p, miR-352, miR-743b-3p, miR-28-5p, miR-291a-3p, miR-702-3p, miR-129-13p, and miR-136. Among the 19 key DEmiRNAs, the roles of five key DEmiRNAs in SCII, including miR-204, miR-30c, miR-21-5p, miR-155-3p, and miR-136, have been investigated. However, the roles of the remaining key DEmiRNAs have not been explored.

Although appeared in three independent datasets, LJA2016, ZGL2020, and HF2020, miR-22-3p showed inconsistent expression trends.

The expression of miR-760-5p has been validated via RT-PCR in HJR2013, and the expression of miR-200b has been validated via RT-PCR in LXQ2015. RT-PCR was adopted to explore the expression of the key DEmiRNAs that have not been studied or validated via RT-PCR. The 
207

208

209

210

211

212

213

214

215

216

217

218

219

220

221

222

223

224

225

226

227

228

229

230

231

results revealed that the expression levels of miR-144-3p, miR-3568, miR-34c-3p, and miR-463 increased significantly at $24 \mathrm{~h}$ following SCII (Figure 3A), while the expression levels of miR291a-3p, miR-702-3p, miR-28-5p, miR-199a-3p, miR-352, miR-743b-3p, miR-125b-2-3p, and miR-129-1-3p decreased significantly at $24 \mathrm{~h}$ following SCII (Figure 3B).

\section{KEGG and GO enrichment analysis of the target genes of DEmiRNAs in SCII}

The target genes of the 19 key DEmiRNAs were predicted on miDRB. The minimum target score was set to 80, and the number of the target gene of the 19 key DEmiRNAs were obtained (Table 3).

According to the KEGG enrichment analysis of the target genes of the upregulated and downregulated DEmiRNAs, the involved pathways in the upregulated DEmiRNAs are cGMPPKG and cAMP signaling pathway and that in the downregulated DEmiRNAs are Chemokine and MAPK signaling pathway. As shown in Figure 4A-4B, GO enrichment analysis results indicated that target genes of the upregulated DEmiRNAs were markedly enriched in biological processes such as brain development and positive regulation of transcription from RNA polymerase II promoter. Target genes of the downregulated DEmiRNAs were mainly enriched in biological processes such as intracellular signal transduction and negative regulation of cell proliferation, as shown in Figure 4C-4D.

\section{Transcription factor analysis of the key DEmiRNAs target genes in SCII}

The transcription factors corresponding to the key DEmiRNAs regulated target genes were analyzed. For the upregulated DEmiRNAs target genes, 11 transcription factor genes with 178 interactions were obtained. For the downregulated DEmiRNAs target genes, 4 transcription factor genes with 37 interactions were formed. Among the 11 transcription factor genes that regulated the key DEmiRNAs regulated target genes, 4 transcription factor genes could regulate the target genes of the upregulated or downregulated DEmiRNAs (Figure 5A). The 4 transcription factors, including SP1, GLI1, GLI2, and FOXO3, had significant regulatory effects 
232 on the target genes of the key DEmiRNAs (Figure 5B).

233 Verification of miR-3568's involvement in SCII

234 For the 19 key DEmiRNAs not studied in SCII, miR-3568 was especially interesting. A previous 235 study found that miR-3568 was upregulated in liver and serum in rats with alcoholic 236 steatohepatitis and associated with MAPK signaling pathway (Chen et al. 2013). The expression 237 of miR-3568 also increased in matrix vesicles (MV) compared with vascular smooth muscle cell 238 (VSMC) in the rats with chronic kidney disease, indicating the role of miR-3568 in vascular 239 calcification and/or MV formation (Chaturvedi et al. 2015). A recent study revealed that miR2403568 expression in simulated IRI-induced H9C2 cardiomyocytes increased in a time-dependent 241 manner, which promotes simulated IRI-induced apoptosis in H9C2 cardiomyocytes through 242 targeting TRIM62 (Li et al. 2020b). Although miR-3568 was upregulated after SCII in rats based 243 on microRNA microarrays results (Chen et al. 2020a; Li et al. 2015b), the expression and 244 potential function of miR-3568 in SCII has not been further explored.

245 Enriched biological processes for the target genes of miR-3568 were obtained through GO 246 analysis. According to the relations between genes and statistically significant biological 247 processes as well as the relations among miR-3568, genes, and biological processes, a miR248 3568-biological processes-gene network was constructed. GO analysis showed that miR-3568 249 target genes were enriched notably in several biological processes $(p<0.05)$, and GATA6, 250 GATA4, and RBPJ were enriched in several biological functions (Figure 6).

251 In addition, the SCII induced severe neurological deficits of lower extremities, while miR-3568 252 AMO improved neurological function (Figure7A). Cleaved caspase-3 was markedly upregulated 253 in SCII compared with the sham group, and miR-3568 AMO reduced cleaved caspase-3 254 expression. Bax expression levels showed similar trends as cleaved caspase-3. Bcl-2 expression 255 levels significantly decreased after SCII, and miR-3568 AMO increased Bcl-2 expression 256 (Figure7B-7E). Moreover, the expression of GATA6, GATA4, and RBPJ decreased after SCII. 257 Intrathecal injection with miR-3568 AMO attenuated this upregulation. The results were shown 
258

259

260

261

262

263

264

265

266

267

268

269

270

271

272

273

274

275

276

277

278

279

280

281

282

283

284

in Figure 8A-8D.

\section{Discussion}

To better understand the key miRNAs and the related molecular mechanism of SCII, 19 DEmiRNAs were identified in the pathogenesis of SCII. Among which, 9 DEmiRNAs were significantly upregulated: miR-144-3p, miR-3568, miR-204, miR-30c, miR-200b, miR-463, miR-760-5p, miR155-3p, and miR-34c-3p; 10 DEmiRNAs were significantly downregulated: miR-125b-2-3p, miR21-5p, miR-199a-3p, miR-352, miR-743b-3p, miR-28-5p, miR-291a-3p, miR-702-3p, miR-1291-3p, and miR-136. The SCII-related functions of miRNAs such as miR-204, miR-30c, miR-21-5p, miR-155-3p, miR-136, and miR-22-3p have been investigated. Inhibition of miR-204 could promote autophagy and anti-apoptosis to mitigate SCII (Yan et al. 2019). Using wild-type (WT) and miR-155 global knockout mice, Awad et al. demonstrated that miR-155 activity accelerates the initial development of edema and the spreading of gray matter damage, and increases the rate of paralysis in a mouse model of thoraco-abdominal aortic aneurysm (Awad et al. 2018). Studies showed that abrogation of miR-30c protected PC12 cells against OGD-induced apoptosis and the inflammatory response and inhibited SCII through modulating SIRT1 (Wang et al. 2019). Functioning as a switch regulating the polarization of reactive astrocytes, miR-21 promoted synapsis formation and nerites growth after acute SCII (Su et al. 2019). Overexpression of miR-21 exerts anti-apoptosis effects on SCII via inhibiting the pro-apoptotic proteins Faslg and PDCD4 (He et al. 2016). miR-136 plays a vital role in CNS diseases and miR-136 overexpression alleviated cell apoptosis induced by SCII via targeting TIMP3 (Jin et al. 2017).

Studies on the other miRNAs are scarce but still far-reaching. Overexpression of miR-144-3p aggravated IRI-induced ischemic brain injury and promoted neurological dysfunction (Yao et al. 2020). Fang Liu et al. found that as a tumor suppressor, overexpression of miR-34c-3p caused a reduction in cell migration and invasion (Liu et al. 2015). miR-463 works as a negative regulator by targeting small proline-rich repeat protein 1A (SPRR1A) in tibial nerve regeneration (Zhao \& Wu 2019). miR-200b suppresses cell proliferation, invasion, and chemoresistance via inhibiting p70S6K1 in lung cancer (Jin et al. 2020). A recent study showed that miR-219a-3p could improve osteoblast differentiation, cellar activity, and ALP activity of BMSCs (Li et al. 2020c). As a tumor suppressor in RCC, miR-28-5p exerts multiple antitumor 
285

286

287

288

289

290

291

292

293

294

295

296

297

298

299

300

301

302

303

304

305

306

307

308

309

310

311

effects by directly inhibiting RAP1B (Wang et al. 2016). In prostate cancer cells, miR-199-3p reduced invasion and proliferation via targeting Smad1 (Qu et al. 2017). Upregulation of miR-352 resulted in autophagic lysosome dysfunction via inhibiting LAMP2 and CTSL1 (Song et al. 2018). Li et al. found that plasma exosomal miR-125b-2-3p could serve as blood-based biomarkers for diagnosing and monitoring ischemic stroke patients ( $\mathrm{Li}$ et al. 2017). miR-129-1-3p functions as a tumor inhibitor via targeting BDKRB2 in gastric cancer (Wang et al. 2014). miR-760 inhibited the neuroprotective effect of NaHS against injury induced by myocardial IRI via reducing the expression of DUSP1 (Ren et al. 2020). There are few studies about miR-702-3p and miR-743b-3p.

Interestingly, miR-22-3p was downregulated in the SCII sample in the data set HF2020 but upregulated in LJA2016 and ZGL2020. The function and expression of miR-22-3p need further exploration. miR-22-3p plays a crucial role in suppressing tumors via inhibiting cellular invasion, migration, and proliferation in hepatocellular carcinoma and melanoma (Chen et al. 2016; Li et al. 2019). It has been reported that miR22 acts as a potential marker in the diagnosis of astrocytoma in the thoracic spinal cord, and miR-22-3p facilitated M2 polarization of macrophages and inhibited inflammation and motor dysfunction, thus alleviating SCII (Fang et al. 2020; Ohnishi et al. 2017).

In the present study, cGMP-PKG and cAMP signaling pathways are involved in the target genes of the upregulated DEmiRNAs, while the Chemokine signaling pathway and MAPK signaling pathway are enrichment pathways of the downregulated DEmiRNAs target genes. The results are consistent with previous studies, which implicate the involvement of the above pathways in SCII (Chen et al. 2020b; Yu et al. 2018). Inhibition of reactive oxygen species reduced the MAPK pathway in the spinal cord following limb IRI in rats (Choi et al. 2015). CXCL13/CXCR5 axis promoted the development of SCII via ERK-mediated pathways (Chen et al. 2020b). During early-phase SCII, CXCL10/CXCR3 axis was related to inflammatory pain (Yu et al. 2018).

Furthermore, the key DEmiRNAs target genes are strongly regulated by transcription factors such as SP1, GLI1, GLI2, and FOXO3. SP1 was reported as a widely expressed DNA-binding protein containing a $\mathrm{C} 2 \mathrm{H} 2$ zinc finger structure, which modulated gene transcription in various physiological and pathological processes (Wang et al. 2020b). SP1 and its family of related protein factors are implicated in various 
312 essential biological processes, such as cell growth, differentiation, carcinogenesis, and apoptosis

313 (Vizcaíno et al. 2015). GLI1 (Glioma-associated oncogene protein 1) family of transcription factors have

314 three members that answer to signaling from Hedgehog and other signaling together, regulating target

315 gene expression (Sterling et al. 2006). GLI1 can be translocated from cytoplasm to nucleus, thus activating

316 the Hedgehog signal pathway and mediating transcription and expression of many nuclear target genes,

317 subsequently regulating cell proliferation, apoptosis, migration, and invasion (Guo et al. 2015; Xu et al.

318 2014a). GLI2 played a significant role in the pathogenesis of cancer, and some studies implicated that

319 GLI2 mediated regulation of cytokines in TME to promote cancer cell biology (Elsawa et al. 2011; Han et

320 al. 2017). FOXOs transcription factors play crucial roles in stress resistance, inflammation, metabolism,

321 autophagy, apoptosis, and proliferation (Zhou et al. 2019). The function of FOXO3 is highly regulated via

322 posttranslational modifications, such as methylation, acetylation, and phosphorylation (Hedrick et al.

323 2012; Tia et al. 2018; Wang et al. 2017). Zhou et al. suggested that the activation of FOXO3 could induce

324 brain autophagy and contribute to brain damage after IRI (Zhou et al. 2019). A recent study demonstrated

325 that pyroptosis of cardiomyocytes in IRI was regulated by miR-149 via the directly targeting of FOXO3

326 (Lin et al. 2019).

327 Among the key DEmiRNAs not studied in SCII, miR-3568 was especially interesting. A recent

328 study showed that miR-3568 markedly aggravated IRI-induced H9C2 cardiomyocytes apoptosis

329 and decreased the expression of Bcl-2 and Survivin (Li et al. 2020b). This study implicated that

330 miR-3568 might have antiapoptotic potentials. One major mechanism of SCII is neuronal

331 apoptosis ( $\mathrm{Li}$ et al. 2018b). In this study, SCII caused severe neurological deficits of lower

332 extremities, while miR-3568 AMO improved neurological function. In addition, cleaved

333 caspase-3 was markedly upregulated in SCII compared to the sham group, and AMO-3568

334 reduced cleaved caspase-3 expression. Bax expression levels showed a similar trend as cleaved

335 caspase-3. Bcl-2 expression levels decreased significantly after SCII and miR-3568 AMO

336 increased Bcl-2 expression. The expression of GATA6, GATA4, and RBPJ decreased after SCII.

337 Intrathecal injection with miR-3568 AMO attenuated this upregulation. The mammalian GATA

338 transcription factors comprised 6 members. Kamnasaran et al. demonstrated the GATA6 nuclear 
339

340

341

342

343

344

345

346

347

348

349

350

351

352

353

354

355

356

357

358

359

360

361

362

363

364

expression in endothelial cells, choroids plexus epithelium, astrocytes, and neurons (Kamnasaran \& Guha 2005). GATA6 upregulated p53 and p21 mRNA to inhibit tumorigenesis in vivo and lung cancer cell growth in vitro (Chen et al. 2020c). GATA4 has been identified as an antiapoptotic protein that protects cardiomyocytes against hypoxia, IRI, and doxorubicin-induced apoptosis (Kobayashi et al. 2006). A study has shown that GATA4 was reduced by OGD/Rinduced neuronal apoptosis, indicating a neuroprotective function of GATA4 (Xiao et al. 2018). RBPJ is a key transcription factor downstream of receptor activation in the canonical Notch signaling pathway (Zheng et al. 2009). RBPJ-deficient pericytes induced pathogenic transformation of the vasculature resembling $\mathrm{CCMs}$ at the morphological and molecular level and contribute to bigger stroke lesions upon ischemic insult (Diéguez-Hurtado et al. 2019). He et al. indicated that the RBPJ-mediated Notch signaling might be involved in reducing cardiomyocyte apoptosis after myocardial infarction (He et al. 2018). Considering previous studies and the results in this study, miR-3568 might be involved in the apoptosis in SCII. GATA6, GATA4, and RBPJ might be the target genes of miR-3568 for regulating apoptosis after SCII.

In conclusion, 19 key miRNAs and the underlying molecular mechanism in the pathogenesis of SCII were explored, which could be potential intervention targets for SCII. Moreover, inhibition of miR-3568, one of 19 key miRNAs, preserved hind limb function after SCII by reducing apoptosis, possibly through regulating GATA6, GATA4, and RBPJ in SCII. miR-3568 may be a potential clinical target for inhibiting apoptosis in SCII.

\section{Conflict of interest}

The authors declare that they have no conflicts of interest. 
365

366

367

368

369

370

371

372

373

374

375

376

377

378

379

380

381

382

383

384

385

386

387

388

389

390

Figure 1. The analysis process of the study. SCII: spinal cord ischemia-reperfusion injury; DEmiRNAs: differentially expressed miRNAs.

Figure 2. Distribution of DEmiRNAs in 23 SCIIs. (A) Upregulation of the proportion of DEmiRNAs in the SCII datasets. A total of 72 upregulated miRNAs were obtained. The number of DEmiRNAs supported by 1 dataset, 2 datasets, and 3 datasets was 51, 9(including an inconsistent expression miRNA: miR-22-3p), and 1. (B) Downregulation of the proportion of DEmiRNAs in the SCII datasets. A total of 79 downregulated miRNAs were obtained. The number of DEmiRNAs supported by 1 dataset, 2 datasets, and 3 datasets was 58, 9, and 1 .

Figure 3. Expression of key DEmiRNAs following SCII. (A) The expression of key upregulated DEmiRNAs following SCII. (B) The expression of key downregulated DEmiRNAs following SCII. $\mathrm{n}=4$ for per group. Data were analyzed with Student's t-test. ${ }^{*} p<0.05$, versus the sham group.

Figure 4. The KEGG pathway analysis and the GO annotations for biological process of top 10 most significant enrichment terms for target genes of DEmiRNAs. (A) KEGG pathway analysis for upregulation DEmiRNAs target genes. (B) KEGG pathway analysis for downregulation DEmiRNAs target genes. (C) The biological process of $\mathrm{GO}$ annotations for upregulation DEmiRNAs target genes. (D) The biological process of GO annotations for downregulation DEmiRNAs target genes.

Figure 5. Transcription factor analysis of key DEmiRNAs target genes in SCII. (A)The Venn Diagram of transcription factors of DEmiRNAs target genes. The purple-blue background represents the number of transcription factor analysis for upregulated DEmiRNAs target genes. The pink background represents the number of transcription factor analysis for downregulated DEmiRNAs target genes. (B) The transcription factor-DEmiRNAs target genes regulation network. The red triangle represents the transcription factor; the purple hexagon represents upregulated DEmiRNAs target genes; the green hexagon represents downregulated DEmiRNAs target genes; the orange hexagon represents target genes of both upregulated and downregulated 
391

392

393

394

395

396

397

398

399

400

401

402

403

404
DEmiRNAs.

Figure 6. A miR-3568-biological processes-gene network.

Figure 7. Effects of AMO-3568 following SCII. (A) Tarlov scores. $n=8$ for per group. (B-E) The protein expression levels of cleaved caspase-3, Bax, and Bcl-2 were measured with Western blot assay. $n=4$ for per group. Data were analyzed with the one-way ANOVA followed by the Tukey's test. ${ }^{*} p<0.05$, versus the sham group, ${ }^{\#} p<0.05$ versus the SCII group.

Figure 8. Effects of AMO-3568 on the protein expression levels of RPBJ (A, B), GATA6(A, C) and GATA4(A, D) were measured by Western blot assay. $n=4$ for per group. Data were analyzed by one-way ANOVA followed by the Tukey's test. ${ }^{*} p<0.05$, versus the sham group, ${ }^{*} p<0.05$ versus the SCII group.

Table 1. The primers used in this study.

Table 2. Basic characteristics of differentially expressed miRNA datasets in SCII.

Table 3. The 19 key DEmiRNAs in SCII. 
Awad H, Bratasz A, Nuovo G, Burry R, Meng X, Kelani H, Brown M, Ramadan ME, Williams J, Bouhliqah L, Popovich PG, Guan Z, McAllister C, Corcoran SE, Kaspar B, Michele Basso D, Otero JJ, Kirsch C, Davis IC, Croce CM, Michaille JJ, and Tili E. 2018. MiR-155 deletion reduces ischemia-induced paralysis in an aortic aneurysm repair mouse model: Utility of immunohistochemistry and histopathology in understanding etiology of spinal cord paralysis. Ann Diagn Pathol 36:12-20. 10.1016/j.anndiagpath.2018.06.002

Balsam LB. 2017. Spinal cord ischemia-reperfusion injury: MicroRNAs and mitophagy at a crossroads. $J$ Thorac Cardiovasc Surg 154:1509-1510. 10.1016/j.jtcvs.2017.06.010

Bao N, Fang B, Lv H, Jiang Y, Chen F, Wang Z, and Ma H. 2018. Upregulation of miR-199a-5p Protects Spinal Cord Against Ischemia/Reperfusion-Induced Injury via Downregulation of ECE1 in Rat. Cell Mol Neurobiol 38:1293-1303. 10.1007/s10571-018-0597-2

Bhalala OG, Srikanth M, and Kessler JA. 2013. The emerging roles of microRNAs in CNS injuries. Nat Rev Neurol 9:328-339. 10.1038/nrneurol.2013.67

Chaturvedi P, Chen NX, O'Neill K, McClintick JN, Moe SM, and Janga SC. 2015. Differential miRNA Expression in Cells and Matrix Vesicles in Vascular Smooth Muscle Cells from Rats with Kidney Disease. PLoS One 10:e0131589. 10.1371/journal.pone.0131589

Chen F, Li X, Li Z, Qiang Z, and Ma H. 2020a. Altered expression of MiR-186-5p and its target genes after spinal cord ischemia-reperfusion injury in rats. Neurosci Lett 718:134669. 10.1016/j.neulet.2019.134669

Chen F, Li X, Li Z, Zhou Y, Qiang Z, and Ma H. 2020b. The roles of chemokine (C-X-C motif) ligand 13 in spinal cord ischemia-reperfusion injury in rats. Brain Res 1727:146489. 10.1016/j.brainres.2019.146489

Chen J, Wu FX, Luo HL, Liu JJ, Luo T, Bai T, Li LQ, and Fan XH. 2016. Berberine upregulates miR-22-3p to suppress hepatocellular carcinoma cell proliferation by targeting Sp1. Am J Transl Res 8:4932-4941.

Chen W, Chen Z, Zhang M, Tian Y, Liu L, Lan R, Zeng G, Fu X, Ru G, Liu W, Chen L, and Fan Z. 2020c. GATA6 Exerts Potent Lung Cancer Suppressive Function by Inducing Cell Senescence. Front Oncol 10:824. 10.3389/fonc. 2020.00824

Chen YP, Jin X, Xiang Z, Chen SH, and Li YM. 2013. Circulating MicroRNAs as potential biomarkers for alcoholic steatohepatitis. Liver Int 33:1257-1265. 10.1111/liv.12196

Choi EK, Yeo JS, Park CY, Na H, Lim J, Lee JE, Hong SW, Park SS, Lim DG, and Kwak KH. 2015. Inhibition of reactive oxygen species downregulates the MAPK pathway in rat spinal cord after limb ischemia reperfusion injury. Int J Surg 22:74-78. 10.1016/j.ijsu.2015.08.016

Diéguez-Hurtado R, Kato K, Giaimo BD, Nieminen-Kelhä M, Arf H, Ferrante F, Bartkuhn M, Zimmermann T, Bixel MG, Eilken HM, Adams S, Borggrefe T, Vajkoczy P, and Adams RH. 2019. Loss of the transcription factor RBPJ induces disease-promoting properties in brain pericytes. Nat Commun 10:2817. 10.1038/s41467-019-10643-w

Elsawa SF, Almada LL, Ziesmer SC, Novak AJ, Witzig TE, Ansell SM, and Fernandez-Zapico ME. 2011. GLI2 transcription factor mediates cytokine cross-talk in the tumor microenvironment. $J$ Biol Chem 286:2152421534. 10.1074/jbc.M111.234146

Fang B, Li XQ, Bi B, Tan WF, Liu G, Zhang Y, and Ma H. 2015. Dexmedetomidine attenuates blood-spinal cord barrier disruption induced by spinal cord ischemia reperfusion injury in rats. Cell Physiol Biochem 36:373383. $10.1159 / 000430107$

Fang H, Yang M, Pan Q, Jin HL, Li HF, Wang RR, Wang QY, and Zhang JP. 2020. MicroRNA-22-3p alleviates spinal cord ischemia/reperfusion injury by modulating M2 macrophage polarization via IRF5. $J$ 
Neurochem. 10.1111/jnc. 15042

Guo A, Wang W, Shi H, Wang J, and Liu T. 2019. Identification of Hub Genes and Pathways in a Rat Model of Renal Ischemia-Reperfusion Injury Using Bioinformatics Analysis of the Gene Expression Omnibus (GEO) Dataset and Integration of Gene Expression Profiles. Med Sci Monit 25:8403-8411. 10.12659/msm.920364

Guo W, Tian H, Dong X, Bai J, and Yang X. 2015. Knockdown of Gli1 by small-interfering RNA enhances the effects of BCNU on the proliferation and apoptosis of glioma U251 cells. Int J Clin Exp Pathol 8:77627773.

Han W, Jackson DA, Matissek SJ, Misurelli JA, Neil MS, Sklavanitis B, Amarsaikhan N, and Elsawa SF. 2017. Novel Molecular Mechanism of Regulation of CD40 Ligand by the Transcription Factor GLI2. J Immunol 198:4481-4489. 10.4049/jimmunol.1601490

He F, Ren Y, Shi E, Liu K, Yan L, and Jiang X. 2016. Overexpression of microRNA-21 protects spinal cords against transient ischemia. $J$ Thorac Cardiovasc Surg 152:1602-1608. 10.1016/j.jtcvs.2016.07.065

He F, Shi E, Yan L, Li J, and Jiang X. 2015. Inhibition of micro-ribonucleic acid-320 attenuates neurologic injuries after spinal cord ischemia. $J$ Thorac Cardiovasc Surg 150:398-406. 10.1016/j.jtcvs.2015.03.066

He Y, Pang S, Huang J, Zhu K, Tong J, Tang Y, Ma G, and Chen L. 2018. Blockade of RBP-J-Mediated Notch Signaling Pathway Exacerbates Cardiac Remodeling after Infarction by Increasing Apoptosis in Mice. Biomed Res Int 2018:5207031. 10.1155/2018/5207031

Hedrick SM, Hess Michelini R, Doedens AL, Goldrath AW, and Stone EL. 2012. FOXO transcription factors throughout T cell biology. Nat Rev Immunol 12:649-661. 10.1038/nri3278

Hu JR, Lv GH, and Yin BL. 2013. Altered microRNA expression in the ischemic-reperfusion spinal cord with atorvastatin therapy. J Pharmacol Sci 121:343-346. 10.1254/jphs.12235sc

Jia H, Ma H, Li Z, Chen F, Fang B, Cao X, Chang Y, and Qiang Z. 2019. Downregulation of LncRNA TUG1 Inhibited TLR4 Signaling Pathway-Mediated Inflammatory Damage After Spinal Cord Ischemia Reperfusion in Rats via Suppressing TRIL Expression. J Neuropathol Exp Neurol 78:268-282. 10.1093/jnen/nly126

Jin HF, Wang JF, Song TT, Zhang J, and Wang L. 2020. MiR-200b Inhibits Tumor Growth and Chemoresistance via Targeting p70S6K1 in Lung Cancer. Front Oncol 10:643. 10.3389/fonc.2020.00643

Jin R, Xu S, Lin X, and Shen M. 2017. MiR-136 controls neurocytes apoptosis by regulating Tissue Inhibitor of Metalloproteinases-3 in spinal cord ischemic injury. Biomed Pharmacother 94:47-54. 10.1016/j.biopha.2017.07.053

Kamnasaran D, and Guha A. 2005. Expression of GATA6 in the human and mouse central nervous system. Brain Res Dev Brain Res 160:90-95. 10.1016/j.devbrainres.2005.07.012

Kobayashi S, Lackey T, Huang Y, Bisping E, Pu WT, Boxer LM, and Liang Q. 2006. Transcription factor gata4 regulates cardiac BCL2 gene expression in vitro and in vivo. Faseb j 20:800-802. 10.1096/fj.05-5426fje

Li DB, Liu JL, Wang W, Li RY, Yu DJ, Lan XY, and Li JP. 2017. Plasma Exosomal miR-422a and miR-125b-2-3p Serve as Biomarkers for Ischemic Stroke. Curr Neurovasc Res 14:330-337. $10.2174 / 1567202614666171005153434$

Li JA, Zan CF, Xia P, Zheng CJ, Qi ZP, Li CX, Liu ZG, Hou TT, and Yang XY. 2016a. Key genes expressed in different stages of spinal cord ischemia/reperfusion injury. Neural Regen Res 11:1824-1829. 10.4103/16735374.194754 
487

Li L, Jiang HK, Li YP, and Guo YP. 2015a. Hydrogen sulfide protects spinal cord and induces autophagy via miR$30 \mathrm{c}$ in a rat model of spinal cord ischemia-reperfusion injury. J Biomed Sci 22:50. 10.1186/s12929-0150135-1

Li R, Zhao K, Ruan Q, Meng C, and Yin F. 2020a. The transcription factor Foxd3 induces spinal cord ischemiareperfusion injury by potentiating microRNA-214-dependent inhibition of Kcnk2. Exp Mol Med 52:118129. $10.1038 / \mathrm{s} 12276-019-0370-8$

Li X-Q, Lv H-W, Tan W-F, Fang B, Wang H, and Ma H. 2014a. Role of the TLR4 pathway in blood-spinal cord barrier dysfunction during the bimodal stage after ischemia/reperfusion injury in rats. Journal of Neuroinflammation 11. 10.1186/1742-2094-11-62

Li X-Q, Wang J, Fang B, Tan W-F, and Ma H. 2014b. Intrathecal antagonism of microglial TLR4 reduces inflammatory damage to blood-spinal cord barrier following ischemia/reperfusion injury in rats. Molecular Brain 7. 10.1186/1756-6606-7-28

Li X, Lou X, Xu S, Wang Q, Shen M, and Miao J. 2018a. Knockdown of miR-372 Inhibits Nerve Cell Apoptosis Induced by Spinal Cord Ischemia/Reperfusion Injury via Enhancing Autophagy by Up-regulating Beclin-1. J Mol Neurosci 66:437-444. 10.1007/s12031-018-1179-y

Li X, Wang X, Liu YS, Wang XD, Zhou J, and Zhou H. 2020b. Downregulation of miR-3568 Protects Against Ischemia/Reperfusion-Induced Cardiac Dysfunction in Rats and Apoptosis in H9C2 Cardiomyocytes Through Targeting TRIM62. Front Pharmacol 11:17. 10.3389/fphar.2020.00017

Li XQ, Fang B, Tan WF, Wang ZL, Sun XJ, Zhang ZL, and Ma H. 2016b. miR-320a affects spinal cord edema through negatively regulating aquaporin-1 of blood-spinal cord barrier during bimodal stage after ischemia reperfusion injury in rats. BMC Neurosci 17:10. 10.1186/s12868-016-0243-1

Li XQ, Lv HW, Wang ZL, Tan WF, Fang B, and Ma H. 2015b. MiR-27a ameliorates inflammatory damage to the blood-spinal cord barrier after spinal cord ischemia: reperfusion injury in rats by downregulating TICAM-2 of the TLR4 signaling pathway. J Neuroinflammation 12:25. 10.1186/s12974-015-0246-3

Li XQ, Yu Q, Tan WF, Zhang ZL, and Ma H. 2018b. MicroRNA-125b mimic inhibits ischemia reperfusion-induced neuroinflammation and aberrant p53 apoptotic signalling activation through targeting TP53INP1. Brain Behav Immun 74:154-165. 10.1016/j.bbi.2018.09.002

Li Z, Tang X, and Duan S. 2019. Interference from LncRNA SPRY4-IT1 restrains the proliferation, migration, and invasion of melanoma cells through inactivating MAPK pathway by up-regulating miR-22-3p. Int $J$ Clin Exp Pathol 12:477-487.

Li ZH, Hu H, Zhang XY, Liu GD, Ran B, Zhang PG, Liao MM, and Wu YC. 2020c. MiR-291a-3p regulates the BMSCs differentiation via targeting DKK1 in dexamethasone-induced osteoporosis. Kaohsiung J Med Sci 36:35-42. 10.1002/kjm2.12134

Lin J, Lin H, Ma C, Dong F, Hu Y, and Li H. 2019. MiR-149 Aggravates Pyroptosis in Myocardial IschemiaReperfusion Damage via Silencing FoxO3. Med Sci Monit 25:8733-8743. 10.12659/msm.918410

Liu F, Wang X, Li J, Gu K, Lv L, Zhang S, Che D, Cao J, Jin S, and Yu Y. 2015. miR-34c-3p functions as a tumour suppressor by inhibiting eIF4E expression in non-small cell lung cancer. Cell Prolif 48:582-592. 10.1111/cpr.12201

Liu K, Yan L, Jiang X, Yu Y, Liu H, Gu T, and Shi E. 2017. Acquired inhibition of microRNA-124 protects against spinal cord ischemia-reperfusion injury partially through a mitophagy-dependent pathway. $J$ Thorac Cardiovasc Surg 154:1498-1508. 10.1016/j.jtcvs.2017.05.046 
Liu Y, Pan L, Jiang A, and Yin M. 2018. Hydrogen sulfide upregulated lncRNA CasC7 to reduce neuronal cell apoptosis in spinal cord ischemia-reperfusion injury rat. Biomed Pharmacother 98:856-862. 10.1016/j.biopha.2017.12.079

Liu ZG, Li Y, Jiao JH, Long H, Xin ZY, and Yang XY. 2020. MicroRNA regulatory pattern in spinal cord ischemiareperfusion injury. Neural Regen Res 15:2123-2130. 10.4103/1673-5374.280323

Ohnishi YI, Iwatsuki K, Ishihara M, Ohkawa T, Kinoshita M, Shinzawa K, Fujimoto Y, and Yoshimine T. 2017. Promotion of astrocytoma cell invasion by micro RNA-22 targeting of tissue inhibitor of matrix metalloproteinase-2. J Neurosurg Spine 26:396-403. 10.3171/2016.8.Spine16248

Qiao Y, Peng C, Li J, Wu D, and Wang X. 2018. LncRNA MALAT1 is Neuroprotective in a Rat Model of Spinal Cord Ischemia-Reperfusion Injury Through miR-204 Regulation. Curr Neurovasc Res 15:211-219. $10.2174 / 1567202615666180712153150$

Qu F, Zheng J, Gan W, Lian H, He H, Li W, Yuan T, Yang Y, Li X, Ji C, Yan X, Xu L, and Guo H. 2017. MiR199a-3p suppresses proliferation and invasion of prostate cancer cells by targeting Smad1. Oncotarget 8:52465-52473. 10.18632/oncotarget.17191

Ren L, Wang Q, Ma L, and Wang D. 2020. MicroRNA-760-mediated low expression of DUSP1 impedes the protective effect of NaHS on myocardial ischemia-reperfusion injury. Biochem Cell Biol 98:378-385. 10.1139/bcb-2019-0310

Smith PD, Puskas F, Meng X, Lee JH, Cleveland JC, Jr., Weyant MJ, Fullerton DA, and Reece TB. 2012. The evolution of chemokine release supports a bimodal mechanism of spinal cord ischemia and reperfusion injury. Circulation 126:S110-117. 10.1161/circulationaha.111.080275

Song Z, Huang Y, Liu C, Lu M, Li Z, Sun B, Zhang W, and Xue D. 2018. miR-352 participates in the regulation of trypsinogen activation in pancreatic acinar cells by influencing the function of autophagic lysosomes. Oncotarget 9:10868-10879. 10.18632/oncotarget.24220

Sterling JA, Oyajobi BO, Grubbs B, Padalecki SS, Munoz SA, Gupta A, Story B, Zhao M, and Mundy GR. 2006. The hedgehog signaling molecule Gli2 induces parathyroid hormone-related peptide expression and osteolysis in metastatic human breast cancer cells. Cancer Res 66:7548-7553. 10.1158/0008-5472.Can-060452

Su Y, Chen Z, Du H, Liu R, Wang W, Li H, and Ning B. 2019. Silencing miR-21 induces polarization of astrocytes to the A2 phenotype and improves the formation of synapses by targeting glypican 6 via the signal transducer and activator of transcription-3 pathway after acute ischemic spinal cord injury. Faseb $j$ 33:10859-10871. 10.1096/fj.201900743R

Tarlov IM. 1972. Acute spinal cord compression paralysis. J Neurosurg 36:10-20. 10.3171/jns.1972.36.1.0010

Tia N, Singh AK, Pandey P, Azad CS, Chaudhary P, and Gambhir IS. 2018. Role of Forkhead Box O (FOXO) transcription factor in aging and diseases. Gene 648:97-105. 10.1016/j.gene.2018.01.051

Vizcaíno C, Mansilla S, and Portugal J. 2015. Sp1 transcription factor: A long-standing target in cancer chemotherapy. Pharmacol Ther 152:111-124. 10.1016/j.pharmthera.2015.05.008

Wang C, Wu C, Yang Q, Ding M, Zhong J, Zhang CY, Ge J, Wang J, and Zhang C. 2016. miR-28-5p acts as a tumor suppressor in renal cell carcinoma for multiple antitumor effects by targeting RAP1B. Oncotarget 7:73888-73902. 10.18632/oncotarget.12516

Wang D, Luo L, and Guo J. 2014. miR-129-1-3p inhibits cell migration by targeting BDKRB2 in gastric cancer. Med Oncol 31:98. 10.1007/s12032-014-0098-1 
Wang J, Nie Z, Zhao H, Gao K, and Cao Y. 2020a. MiRNA-125a-5p attenuates blood-spinal cord barrier permeability under hypoxia in vitro. Biotechnol Lett 42:25-34. 10.1007/s10529-019-02753-8

Wang R, Yang Y, Wang H, He Y, and Li C. 2020b. MiR-29c protects against inflammation and apoptosis in Parkinson's disease model in vivo and in vitro by targeting SP1. Clin Exp Pharmacol Physiol 47:372-382. $10.1111 / 1440-1681.13212$

Wang X, Hu S, and Liu L. 2017. Phosphorylation and acetylation modifications of FOXO3a: Independently or synergistically? Oncol Lett 13:2867-2872. 10.3892/ol.2017.5851

Wang X, Su X, Gong F, Yin J, Sun Q, Lv Z, and Liu B. 2019. MicroRNA-30c abrogation protects against spinal cord ischemia reperfusion injury through modulating SIRT1. Eur $J$ Pharmacol 851:80-87. 10.1016/j.ejphar.2019.02.027

Wang Y, Pang QJ, Liu JT, Wu HH, and Tao DY. 2018. Down-regulated miR-448 relieves spinal cord ischemia/reperfusion injury by up-regulating SIRT1. Braz J Med Biol Res 51:e7319. 10.1590/1414$431 \times 20177319$

Xiao J, Kong R, and Hu J. 2018. Inhibition of microRNA-429 attenuates oxygen-glucose deprivation/reoxygenationinduced neuronal injury by promoting expression of GATA-binding protein 4. Neuroreport 29:723-730. 10.1097/wnr.0000000000001023

Xu HS, Zong HL, Shang M, Ming X, Zhao JP, Ma C, and Cao L. 2014a. MiR-324-5p inhibits proliferation of glioma by target regulation of GLI1. Eur Rev Med Pharmacol Sci 18:828-832.

Xu J, Huang G, Zhang K, Sun J, Xu T, Li R, Tao H, and Xu W. 2014b. Nrf2 activation in astrocytes contributes to spinal cord ischemic tolerance induced by hyperbaric oxygen preconditioning. J Neurotrauma 31:13431353. 10.1089/neu.2013.3222

Yan L, Shi E, Jiang X, Shi J, Gao S, and Liu H. 2019. Inhibition of MicroRNA-204 Conducts Neuroprotection Against Spinal Cord Ischemia. Ann Thorac Surg 107:76-83. 10.1016/j.athoracsur.2018.07.082

Yao P, Li YL, Chen Y, Shen W, Wu KY, and Xu WH. 2020. Overexpression of long non-coding RNA Rian attenuates cell apoptosis from cerebral ischemia-reperfusion injury via Rian/miR-144-3p/GATA3 signaling. Gene 737:144411. 10.1016/j.gene.2020.144411

Yu Q, Tian DL, Tian Y, Zhao XT, and Yang XY. 2018. Elevation of the Chemokine Pair CXCL10/CXCR3 Initiates Sequential Glial Activation and Crosstalk During the Development of Bimodal Inflammatory Pain after Spinal Cord Ischemia Reperfusion. Cell Physiol Biochem 49:2214-2228. 10.1159/000493825

Zhai F, Zhang X, Guan Y, Yang X, Li Y, Song G, and Guan L. 2012. Expression profiles of microRNAs after focal cerebral ischemia/reperfusion injury in rats. Neural Regen Res 7:917-923. 10.3969/j.issn.16735374.2012.12.007

Zhao J, and Wu C. 2019. MiR-463-3p inhibits tibial nerve regeneration via post-transcriptional suppression of SPRR1A. Artif Cells Nanomed Biotechnol 47:3631-3637. 10.1080/21691401.2019.1657874

Zhao L, Jiang X, Shi J, Gao S, Zhu Y, Gu T, and Shi E. 2019. Exosomes derived from bone marrow mesenchymal stem cells overexpressing microRNA-25 protect spinal cords against transient ischemia. $J$ Thorac Cardiovasc Surg 157:508-517. 10.1016/j.jtcvs.2018.07.095

Zheng MH, Shi M, Pei Z, Gao F, Han H, and Ding YQ. 2009. The transcription factor RBP-J is essential for retinal cell differentiation and lamination. Mol Brain 2:38. 10.1186/1756-6606-2-38

Zhou H, Wang X, Ma L, Deng A, Wang S, and Chen X. 2019. FoxO3 transcription factor promotes autophagy after transient cerebral ischemia/reperfusion. Int J Neurosci 129:738-745. 10.1080/00207454.2018.1564290

PeerJ reviewing PDF | (2020:11:55270:2:0:NEW 18 Apr 2021) 
611 


\section{Table 1 (on next page)}

Table 1. The primers used in this study. 
Table 1. The primers used in this study.

\begin{tabular}{|c|c|c|}
\hline miRNA/gene & Forward primer & Reverse primer \\
\hline miR-3568 & TGTTCTTCCCGTGCAGAAG & \\
\hline miR-144-3p & CGCGCGTACAGTATAGATGATGTA & \\
\hline miR-34c-3p & TAATCACTAACCACACAGCCAGG & \\
\hline miR-463 & CTTGATAGACGCCAATTTGGGTAG & \\
\hline miR-291a-3p & AAAGTGCTTCCACTTTGTGTGC & \\
\hline miR-702-3p & TATATATGCCCACCCTTTACCCC & \\
\hline miR-28-5p & CGAAGGAGCTCACAGTCTATTGA & \\
\hline miR-199a-3p & CGACAGTAGTCTGCACATTGGTTA & \\
\hline miR-352 & CGCGAAAGACACCATACTGAATAGA & \\
\hline miR-743b-3p & ACAAGTCAGGCTCTTGGGA & \\
\hline miR-125b-2-3p & CGAAGCCCTTACCCCAAAAAG & \\
\hline miR-129-1-3p &
\end{tabular}

* GATA6: GATA-binding protein 6; GATA4: GATA-binding protein 4; RBPJ: Recombination signal-binding protein. 
Table 2 (on next page)

Table 2. Basic characteristics of SCII differentially expressed miRNA datasets. 
Table 2. Basic characteristics of SCII differentially expressed miRNA datasets.

\begin{tabular}{|c|c|c|c|c|c|c|c|}
\hline Refs & $\begin{array}{l}\text { Data } \\
\text { set }\end{array}$ & animals & SCII mode1 & $\begin{array}{l}\text { Time } \\
\text { points }\end{array}$ & Samples & $\begin{array}{l}\text { Assay/seque } \\
\text { ncing type }\end{array}$ & Validated \\
\hline $\begin{array}{l}\text { (Hu et al. } \\
\text { 2013) }\end{array}$ & HJR2013 & Rat & $\begin{array}{l}\text { ligation of abdominal aorta just below the } \\
\text { left renal artery }\end{array}$ & $48 \mathrm{~h}$ after $\mathrm{SCII}$ & $\begin{array}{l}\text { Spinal cord } \\
\text { tissues }\end{array}$ & $\begin{array}{l}\text { microRNA } \\
\text { microarrays }\end{array}$ & $\begin{array}{l}\text { real-time } \\
\text { qRT-PCR }\end{array}$ \\
\hline $\begin{array}{l}\text { (Li et al. } \\
\text { 2015a) }\end{array}$ & LL2015 & $\begin{array}{l}\text { Male SD } \\
\text { rats }(300 \\
\text { to } 350 \mathrm{~g})\end{array}$ & $\begin{array}{l}\text { inserting } 2 \text { F-Fogarty balloon catheters } \\
\text { through the left femoral artery into the } \\
\text { proximal descending thoracic aorta. }\end{array}$ & $48 \mathrm{~h}$ after SCII & $\begin{array}{l}\text { Spinal cord } \\
\text { tissues }\end{array}$ & qRT-PCR & - \\
\hline $\begin{array}{l}\text { (Li et al. } \\
\text { 2015b) }\end{array}$ & LXQ2015 & $\begin{array}{l}\text { Male SD } \\
\text { rats }(200 \\
\text { to } 250 \mathrm{~g})\end{array}$ & $\begin{array}{l}\text { the aortic arch was } \\
\text { cross-clamped between the left common } \\
\text { carotid artery and } \\
\text { left subclavian artery }\end{array}$ & $\begin{array}{l}24 \mathrm{~h} \text { and } 48 \mathrm{~h} \\
\text { after SCII }\end{array}$ & $\begin{array}{l}\text { Spinal cord } \\
\text { tissues }\end{array}$ & $\begin{array}{l}\text { microRNA } \\
\text { microarrays }\end{array}$ & qRT-PCR \\
\hline $\begin{array}{l}\text { (Li et al. } \\
\text { 2016a) }\end{array}$ & LJA2016 & $\begin{array}{l}\text { Male SD } \\
\text { rats }(280 \\
\text { to } 300 \mathrm{~g})\end{array}$ & occluding the abdominal aorta & $\begin{array}{l}0 \mathrm{~h}, 24 \mathrm{~h} \text { and } \\
48 \mathrm{~h} \text { after SCII }\end{array}$ & $\begin{array}{l}\text { Spinal cord } \\
\text { tissues }\end{array}$ & $\begin{array}{l}\text { microarray } \\
\text { analysis }\end{array}$ & - \\
\hline $\begin{array}{l}\text { (Li et al. } \\
\text { 2016b) }\end{array}$ & LXQ2016 & $\begin{array}{l}\text { Male SD } \\
\text { rats }(200 \\
\text { to } 250 \mathrm{~g})\end{array}$ & $\begin{array}{l}\text { the aortic arch was } \\
\text { cross-clamped between the left common } \\
\text { carotid artery and } \\
\text { left subclavian artery }\end{array}$ & $\begin{array}{l}12 \mathrm{~h} \text { and } 48 \mathrm{~h} \\
\text { after SCII }\end{array}$ & $\begin{array}{l}\text { Spinal cord } \\
\text { tissues }\end{array}$ & $\begin{array}{l}\text { microRNA } \\
\text { microarrays }\end{array}$ & qRT-PCR \\
\hline $\begin{array}{l}\text { (He et al. } \\
2016)\end{array}$ & HF2016 & $\begin{array}{l}\text { Male } \\
\text { Wistar } \\
\text { rats }(250 \\
\text { g) }\end{array}$ & $\begin{array}{l}\text { the aortic arch was } \\
\text { cross-clamped between the left common } \\
\text { carotid artery and } \\
\text { left subclavian artery }\end{array}$ & $2 \mathrm{~h}$ after SCII & $\begin{array}{l}\text { Spinal cord } \\
\text { tissues }\end{array}$ & qRT-PCR & - \\
\hline $\begin{array}{l}\text { (Liu et al. } \\
\text { 2017) }\end{array}$ & LK2017 & $\begin{array}{l}\text { Male } \\
\text { Wistar } \\
\text { rats }(250 \\
\text { g) }\end{array}$ & $\begin{array}{l}\text { cross clamping the descending } \\
\text { aorta just distal to the left subclavian artery }\end{array}$ & $48 \mathrm{~h}$ after SCII & $\begin{array}{l}\text { Spinal cord } \\
\text { tissues }\end{array}$ & qRT-PCR & - \\
\hline
\end{tabular}




\begin{tabular}{|c|c|c|c|c|c|c|c|}
\hline $\begin{array}{l}(\text { Jin et } \\
\text { al. } \\
\text { 2017) }\end{array}$ & JRL2017 & $\begin{array}{l}\text { Male SD } \\
\text { rats }\end{array}$ & $\begin{array}{l}\text { clamping the nontraumatic vascular clip on } \\
\text { the abdominal aorta }\end{array}$ & $\begin{array}{l}20 \text { days after } \\
\text { SCII }\end{array}$ & $\begin{array}{l}\text { Spinal cord } \\
\text { tissues }\end{array}$ & RT-PCR & - \\
\hline $\begin{array}{l}\text { (Wang } \\
\text { et al. } \\
2018)\end{array}$ & WY2018 & $\begin{array}{l}\text { Male SD } \\
\text { rats }(250 \\
\text { to } 320 \mathrm{~g})\end{array}$ & $\begin{array}{l}\text { clamping the abdominal aorta with a } \\
\text { bulldog clamp }\end{array}$ & NA & $\begin{array}{l}\text { Spinal cord } \\
\text { tissues }\end{array}$ & qRT-PCR & - \\
\hline $\begin{array}{l}\text { (Zhao } \\
\text { et al. } \\
2019)\end{array}$ & ZLL2018 & $\begin{array}{l}\text { Male SD } \\
\text { rats } \\
\text { (approxim } \\
\text { ately } 250 \\
\text { g) }\end{array}$ & $\begin{array}{l}\text { cross clamping the descending } \\
\text { aorta just distal to the left subclavian artery }\end{array}$ & $6 \mathrm{~h}$ after SCII & $\begin{array}{l}\text { Spinal cord } \\
\text { tissues }\end{array}$ & qRT-PCR & - \\
\hline $\begin{array}{l}\text { (He et } \\
\text { al. } \\
2015 \text { ) }\end{array}$ & HF2018 & $\begin{array}{l}\text { Male } \\
\text { Wistar } \\
\text { rats }(230 \\
\text { to } 270 \mathrm{~g})\end{array}$ & $\begin{array}{l}\text { cross-clamping the descending aorta just } \\
\text { distal to the left subclavian artery }\end{array}$ & $\begin{array}{l}6 \mathrm{~h}, 12 \mathrm{~h}, 24 \mathrm{~h} \\
\text { and } 48 \mathrm{~h} \text { after } \\
\text { SCII }\end{array}$ & $\begin{array}{l}\text { Spinal cord } \\
\text { tissues }\end{array}$ & qRT-PCR & - \\
\hline $\begin{array}{l}\text { (Yan et } \\
\text { al. } \\
\text { 2019) }\end{array}$ & YLH2018 & $\begin{array}{l}\text { Male } \\
\text { Wistar } \\
\text { rats (abo } \\
\text { ut } 250 \mathrm{~g})\end{array}$ & $\begin{array}{l}\text { cross-clamping the descending aorta just } \\
\text { distal to the left subclavian artery }\end{array}$ & $\begin{array}{l}6 \mathrm{~h}, 12 \mathrm{~h}, 24 \mathrm{~h} \\
\text { and } 48 \mathrm{~h} \text { after } \\
\text { SCII }\end{array}$ & $\begin{array}{l}\text { Spinal cord } \\
\text { tissues }\end{array}$ & qRT-PCR & - \\
\hline $\begin{array}{l}\text { (Li et } \\
\text { al. } \\
\text { 2018a) }\end{array}$ & LXG2018 & $\begin{array}{l}\text { SD rats } \\
\text { ( } 200 \text { to } 220 \\
\text { g) }\end{array}$ & $\begin{array}{l}\text { The aortic arch was exposed through a } \\
\text { cervicothoracic approach and cross-clamped } \\
\text { between the left common carotid artery and } \\
\text { the left subclavian artery }\end{array}$ & $48 \mathrm{~h}$ after SCII & $\begin{array}{l}\text { Spinal cord } \\
\text { tissues }\end{array}$ & qRT-PCR & - \\
\hline $\begin{array}{l}\text { (Li et } \\
\text { al. } \\
\text { 2018b) }\end{array}$ & LXQ2018 & $\begin{array}{l}\text { SD rats } \\
(200 \text { to } \\
250 \mathrm{~g}, 8 \\
\text { weeks) }\end{array}$ & $\begin{array}{l}\text { the aortic arch was cross-clamped between the } \\
\text { left common carotid artery and } \\
\text { left subclavian artery }\end{array}$ & $\begin{array}{l}12 \mathrm{~h}, 24 \mathrm{~h}, 36 \\
\mathrm{~h} \text { and } 48 \mathrm{~h} \\
\text { after SCII }\end{array}$ & $\begin{array}{l}\text { Spinal cord } \\
\text { tissues }\end{array}$ & qRT-PCR & - \\
\hline (Liu et & LY2018 & Rat & A 2 F-Fogarty balloon catheter was used to & $48 \mathrm{~h}$ after SCII & Spinal cord & RT-PCR & - \\
\hline
\end{tabular}




\begin{tabular}{|c|c|c|c|c|c|c|c|}
\hline $\begin{array}{l}\text { al. } \\
2018)\end{array}$ & & & $\begin{array}{l}\text { induce spinal cord ischemia through the } \\
\text { left femoral artery into the proximal } \\
\text { descending thoracic aorta }\end{array}$ & & tissues & & \\
\hline $\begin{array}{l}\text { (Qiao } \\
\text { et al. } \\
2018)\end{array}$ & QY2018 & $\begin{array}{l}\text { Male SD } \\
\text { rats }(220 \\
\text { to } 280 \mathrm{~g}) \\
\end{array}$ & occluding the abdominal aorta & $24 \mathrm{~h}$ after SCII & $\begin{array}{l}\text { Spinal cord } \\
\text { tissues }\end{array}$ & $\mathrm{RT}-\mathrm{qPCR}$ & - \\
\hline $\begin{array}{l}\text { (Bao et } \\
\text { al. } \\
\text { 2018) }\end{array}$ & BN2018 & $\begin{array}{l}\text { Male SD } \\
\text { rats }(220 \\
\text { to } 280 \mathrm{~g})\end{array}$ & occluding the aortic arch & $24 \mathrm{~h}$ after SCII & $\begin{array}{l}\text { Spinal cord } \\
\text { tissues }\end{array}$ & $\begin{array}{l}\text { microRNA } \\
\text { microarrays }\end{array}$ & qRT-PCR \\
\hline $\begin{array}{l}\text { (Wang } \\
\text { et al. } \\
2019 \text { ) }\end{array}$ & WXY2019 & $\begin{array}{l}\text { Male SD } \\
\text { rats }(250 \\
\text { to } 300 \mathrm{~g})\end{array}$ & $\begin{array}{l}\text { occluding between the left common carotid } \\
\text { artery and left } \\
\text { subclavian artery }\end{array}$ & $\begin{array}{l}0 \mathrm{~h}, 12 \mathrm{~h}, 24 \mathrm{~h} \\
\text { and } 48 \mathrm{~h} \text { after } \\
\text { SCII }\end{array}$ & $\begin{array}{l}\text { Spinal cord } \\
\text { tissues }\end{array}$ & qRT-PCR & - \\
\hline $\begin{array}{l}\text { (Wang } \\
\text { et al. } \\
2020)\end{array}$ & WJ2020 & - & Model of BSCB under hypoxia & - & $\begin{array}{l}\text { Rat spinal } \\
\text { cord } \\
\text { microvascular } \\
\text { endothelial } \\
\text { cells and } \\
\text { astrocyte }\end{array}$ & RT-PCR & - \\
\hline $\begin{array}{l}\text { (Chen } \\
\text { et al. } \\
2020)\end{array}$ & CFS2020 & $\begin{array}{l}\text { Male SD } \\
\text { rats }(200 \\
\text { to } 250 \mathrm{~g})\end{array}$ & $\begin{array}{l}\text { the aortic arch was cross-clamped between the } \\
\text { left common carotid artery and left subclavian } \\
\text { artery }\end{array}$ & $\begin{array}{l}6 \mathrm{~h}, 12 \mathrm{~h}, 24 \mathrm{~h} \\
36 \mathrm{~h}, 48 \mathrm{~h} \text { and } \\
72 \mathrm{~h} \text { after SCII }\end{array}$ & $\begin{array}{l}\text { Spinal cord } \\
\text { tissues }\end{array}$ & $\begin{array}{l}\text { microRNA } \\
\text { microarrays }\end{array}$ & qRT-PCR \\
\hline $\begin{array}{l}\text { (Li et } \\
\text { al. } \\
2020)\end{array}$ & LR2020 & $\begin{array}{l}\text { Male SD } \\
\text { rats ( } 8 \\
\text { weeks) }\end{array}$ & $\begin{array}{l}\text { the abdominal aorta was ligated } \\
\text { with a } 10 \text {-g bulldog clamp below the renal } \\
\text { artery }\end{array}$ & $1 \mathrm{~h}$ after SCII & $\begin{array}{l}\text { Spinal cord } \\
\text { tissues }\end{array}$ & RT-qPCR & - \\
\hline $\begin{array}{l}\text { (Fang } \\
\text { et al. } \\
2020)\end{array}$ & HF2020 & $\begin{array}{l}\text { Male SD } \\
\text { rats }(250- \\
260 \mathrm{~g})\end{array}$ & $\begin{array}{l}\text { occluding between the left carotid artery } \\
\text { and the left subclavian artery }\end{array}$ & $48 \mathrm{~h}$ after SCII & $\begin{array}{l}\text { Spinal cord } \\
\text { tissues }\end{array}$ & RT-qPCR & - \\
\hline (Liu et & ZGL2020 & Male SD & The abdominal aorta was cross-clamped & $24 \mathrm{~h}$ and $48 \mathrm{~h}$ & Spinal cord & microRNA & qRT-PCR \\
\hline
\end{tabular}




\begin{tabular}{|l|l|l|l|l|l|l|l|}
\hline $\begin{array}{l}\text { al. } \\
2020)\end{array}$ & $\begin{array}{l}\text { rats }(220- \\
280 \mathrm{~g})\end{array}$ & $\begin{array}{l}\text { between the left renal artery and origin of } \\
\text { the right renal artery }\end{array}$ & after SCII & tissues & microarrays & \\
\hline
\end{tabular}


Table 3 (on next page)

Table 3.19 key DEmiRNAs in SCII 
Table 3.19 key DEmiRNAs in SCII

\begin{tabular}{|c|c|c|c|c|c|c|c|}
\hline $\begin{array}{c}\text { up } \\
\text { DEmiRNAs }\end{array}$ & $\begin{array}{c}\text { number target genes } \\
\text { in miRDB (target } \\
\text { score } \geqslant 80)\end{array}$ & $\begin{array}{l}\text { studied } \\
\text { separately } \\
\text { or not }\end{array}$ & $\begin{array}{c}\text { The number } \\
\text { of } \\
\text { datasheets } \\
\text { which } \\
\text { supported }\end{array}$ & $\begin{array}{c}\text { down } \\
\text { DEmiRNAs }\end{array}$ & $\begin{array}{c}\text { number target } \\
\text { genes in } \\
\text { miRDB (target } \\
\text { score } \geqslant 80)\end{array}$ & $\begin{array}{l}\text { studied } \\
\text { separately } \\
\text { or not }\end{array}$ & $\begin{array}{c}\text { The number } \\
\text { of } \\
\text { datasheets } \\
\text { which } \\
\text { supported }\end{array}$ \\
\hline $\mathrm{miR}-144-3 p$ & 168 & NO & 2 & miR-291a-3p & 93 & NO & 2 \\
\hline miR-3568 & 89 & NO & 2 & miR-702-3p & 39 & NO & 2 \\
\hline miR-204 & 166 & YES & 2 & miR-21-5p & 66 & YES & 3 \\
\hline miR-30c & 348 & YES & 3 & miR-28-5p & 19 & NO & 2 \\
\hline $\operatorname{miR}-34 c-3 p$ & 29 & NO & 2 & miR-199a-3p & 60 & NO & 2 \\
\hline $\operatorname{miR}-155-3 p$ & 15 & YES & 2 & miR-352 & 21 & NO & 2 \\
\hline miR-760-5p & 27 & NO & 2 & miR-743b-3p & 134 & NO & 2 \\
\hline miR-463 & 23 & NO & 2 & $m i R-125 b-2-3 p$ & 55 & NO & 2 \\
\hline \multirow[t]{2}{*}{$\mathrm{miR}-200 \mathrm{~b}$} & 190 & NO & 2 & miR-129-1-3p & 39 & NO & 2 \\
\hline & & & & miR-136 & 35 & YES & 2 \\
\hline
\end{tabular}

2 
Figure 1

Figure 1. The analysis process of the study. SCIl: spinal cord ischemia-reperfusion injury; DEmiRNAs: differentially expressed miRNAs.

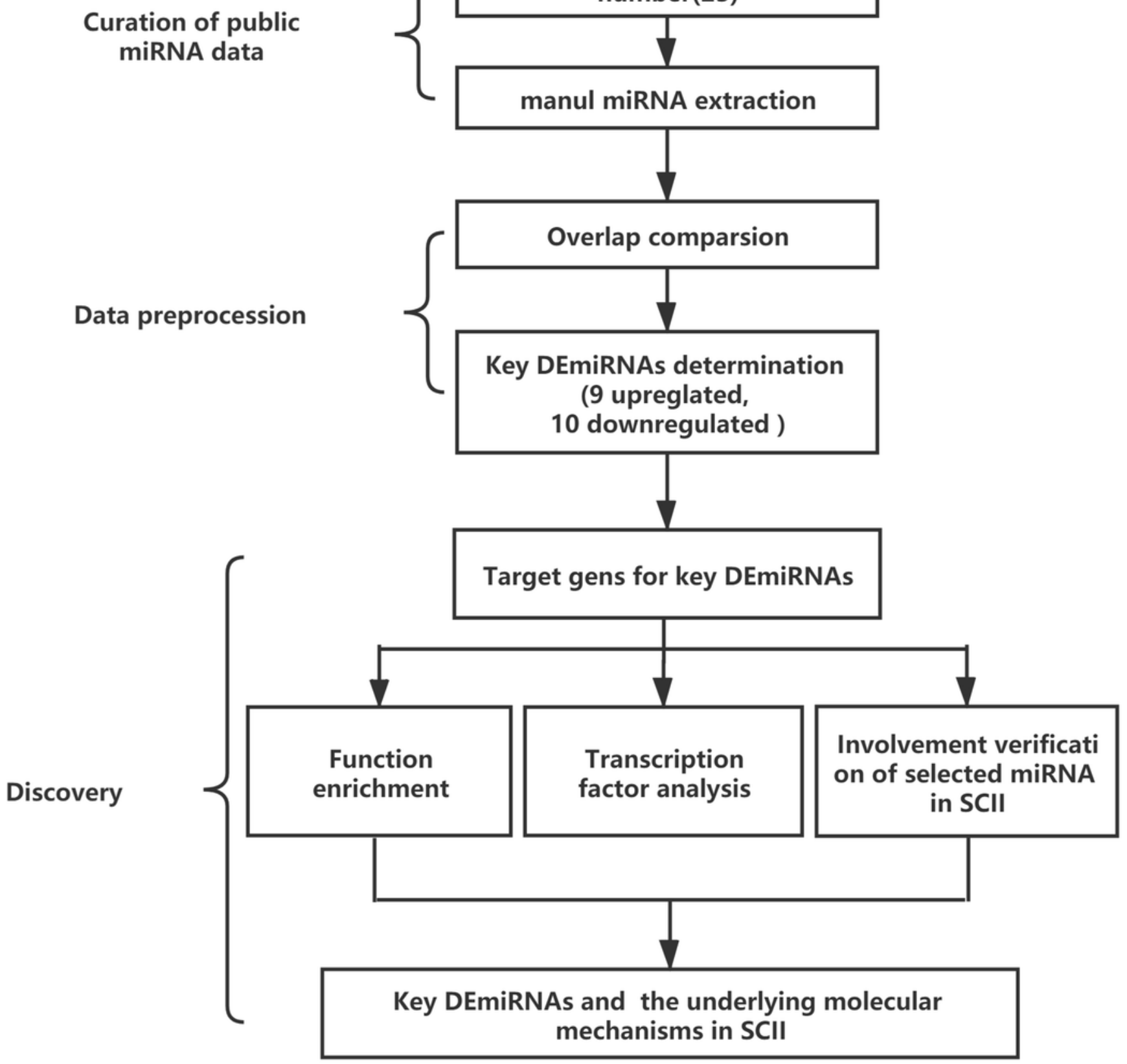




\section{Figure 2}

Figure 2. Distribution of DEmiRNAs in 23 SClls.

Distribution of DEmiRNAs in 23 SClls. (A) Upregulation of the proportion of DEmiRNAs in the SCII datasets. A total of 72 upregulated miRNAs were obtained. The number of DEmiRNAs supported by 1 dataset, 2 datasets, and 3 datasets was 51, 9(including an inconsistent expression miRNA: miR-22-3p), and 1. (B) Downregulation of the proportion of DEmiRNAs in the SCII datasets. A total of 79 downregulated miRNAs were obtained. The number of DEmiRNAs supported by 1 dataset, 2 datasets, and 3 datasets was 58, 9, and 1 .

A

upregulated

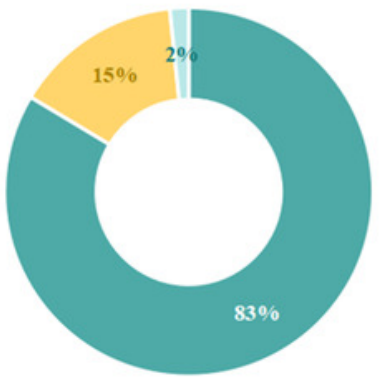

B downregulated

ane dataset support

w two dataset support

= three dataset support

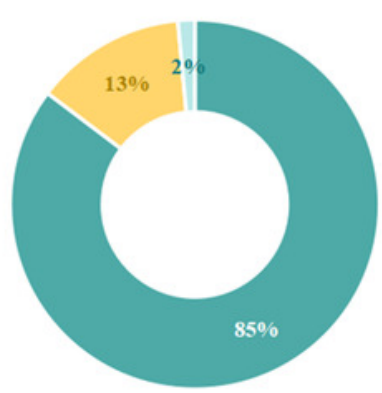

n one dataset support

= two dataset support

three dataset support 
Figure 3

Figure 3. Expression of key DEmiRNAs following SCII.

Expression of key DEmiRNAs following SCII. (A) The expression of key upregulated DEmiRNAs following SCII. (B) The expression of key downregulated DEmiRNAs following SCII. $n=4$ for per group. Data were analyzed with Student's t-test. ${ }^{*} p<0.05$, versus the sham group.

A

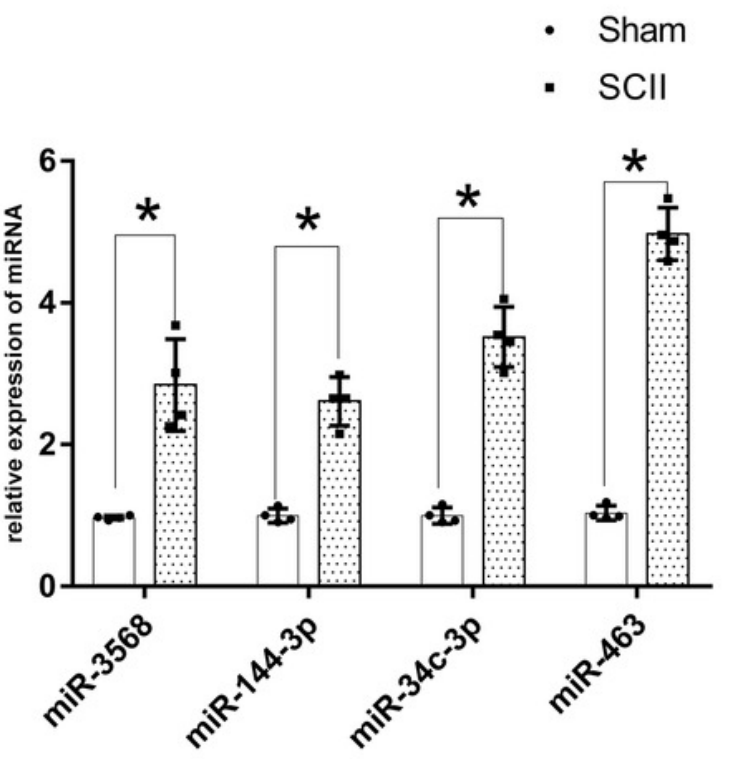

B

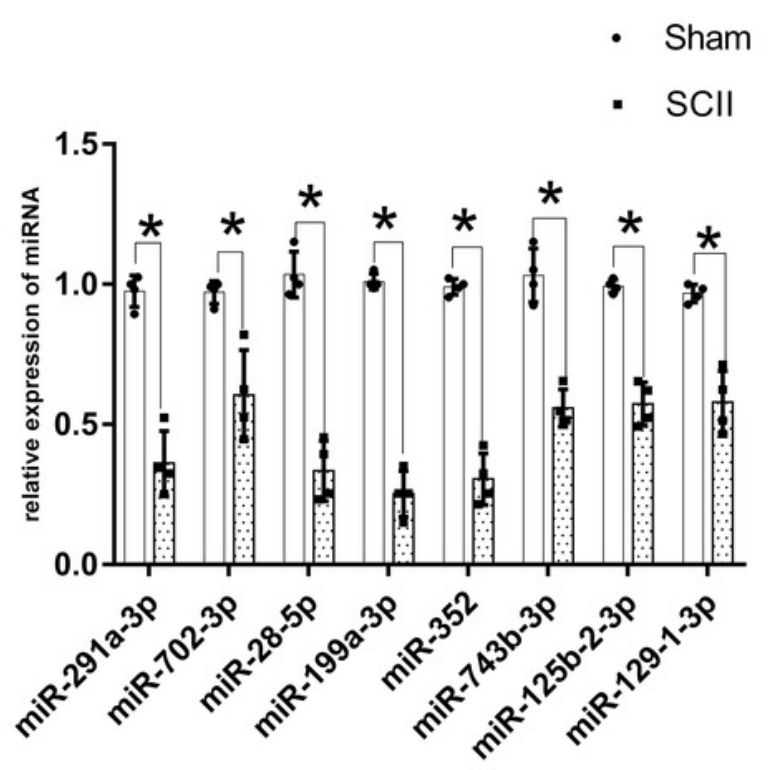




\section{Figure 4}

Figure 4. The KEGG pathway analysis and the GO annotations for biological process of top 10 most significant enrichment terms for target genes of DEmiRNAs.

The KEGG pathway analysis and the GO annotations for biological process of top 10 most significant enrichment terms for target genes of DEmiRNAs. (A) KEGG pathway analysis for upregulation DEmiRNAs target genes. (B) KEGG pathway analysis for downregulation DEmiRNAs target genes. (C) The biological process of $\mathrm{GO}$ annotations for upregulation DEmiRNAs target genes. (D) The biological process of $\mathrm{GO}$ annotations for downregulation DEmiRNAs target genes. 
A

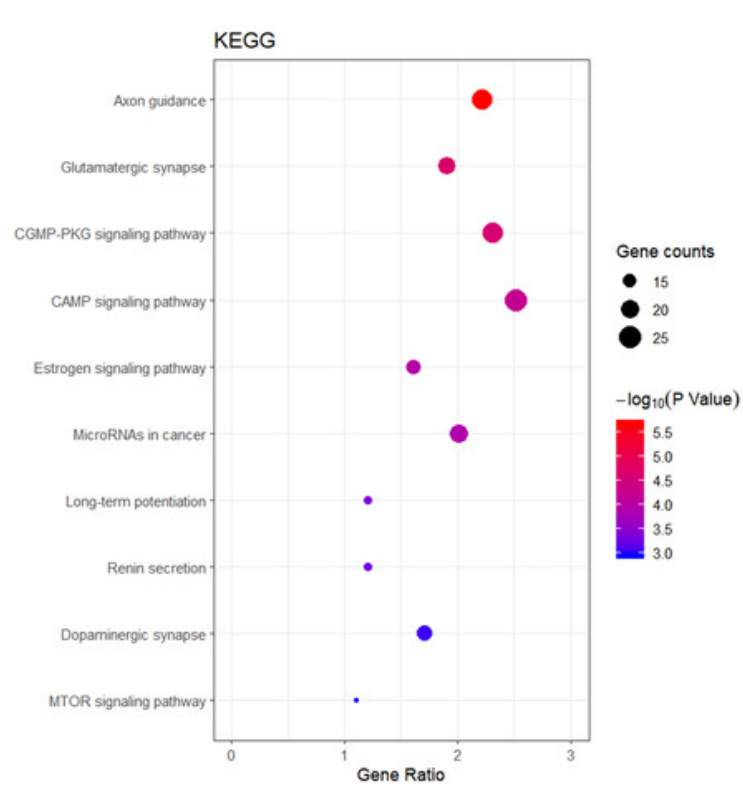

C

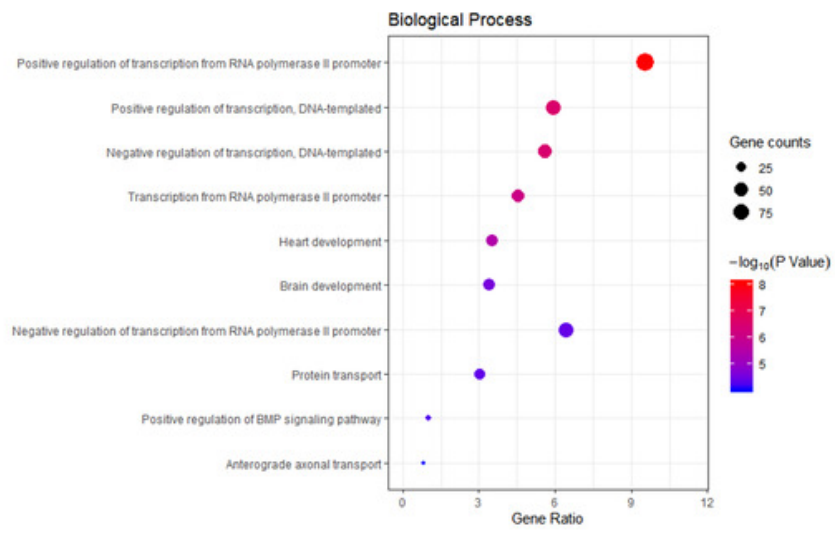

B

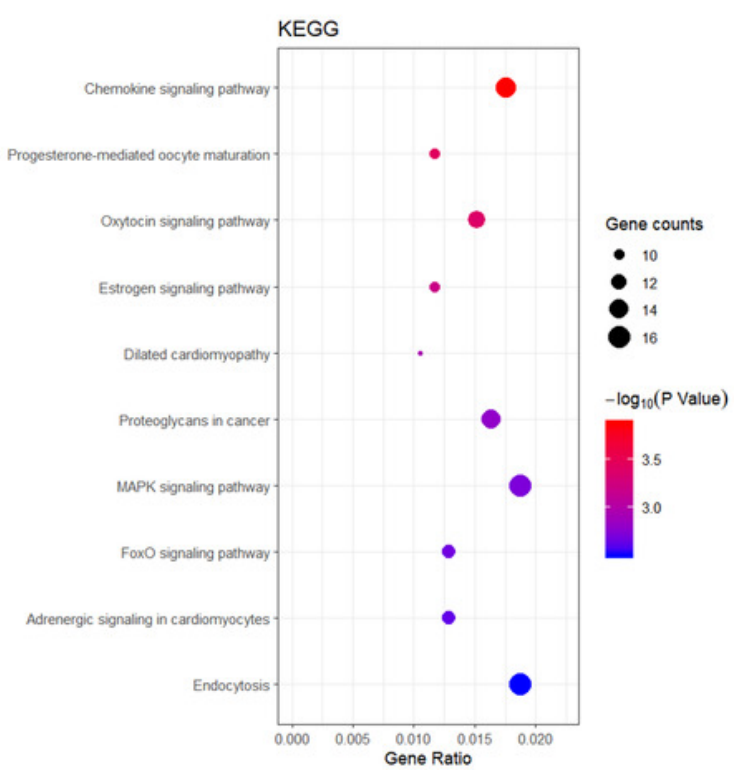

D

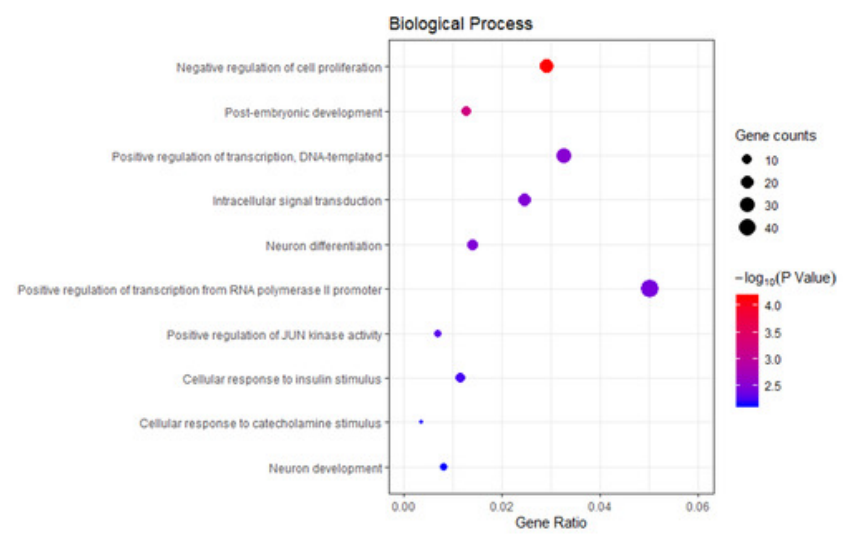




\section{Figure 5}

Figure 5. Transcription factor analysis of key DEmiRNAs target genes in SCII.

Transcription factor analysis of key DEmiRNAs target genes in SCII. (A)The VennDiagramof transcription factors of DEmiRNAs target genes. The purple-blue background represents the number of transcription factor analysis for upregulated DEmiRNAs target genes. The pink background represents the number of transcription factor analysis for downregulated DEmiRNAs target genes. (B) The transcription factor-DEmiRNAs target genes regulation network. The redtriangle represents the transcription factor; the purple hexagon represents upregulated DEmiRNAs target genes; the green hexagon represents downregulated DEmiRNAs target genes; the orange hexagon represents target genes of both upregulated and downregulated DEmiRNAs.

A

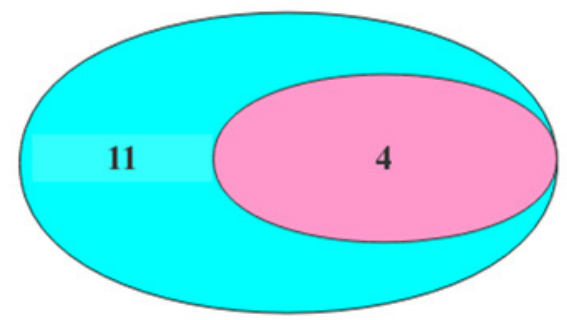

B
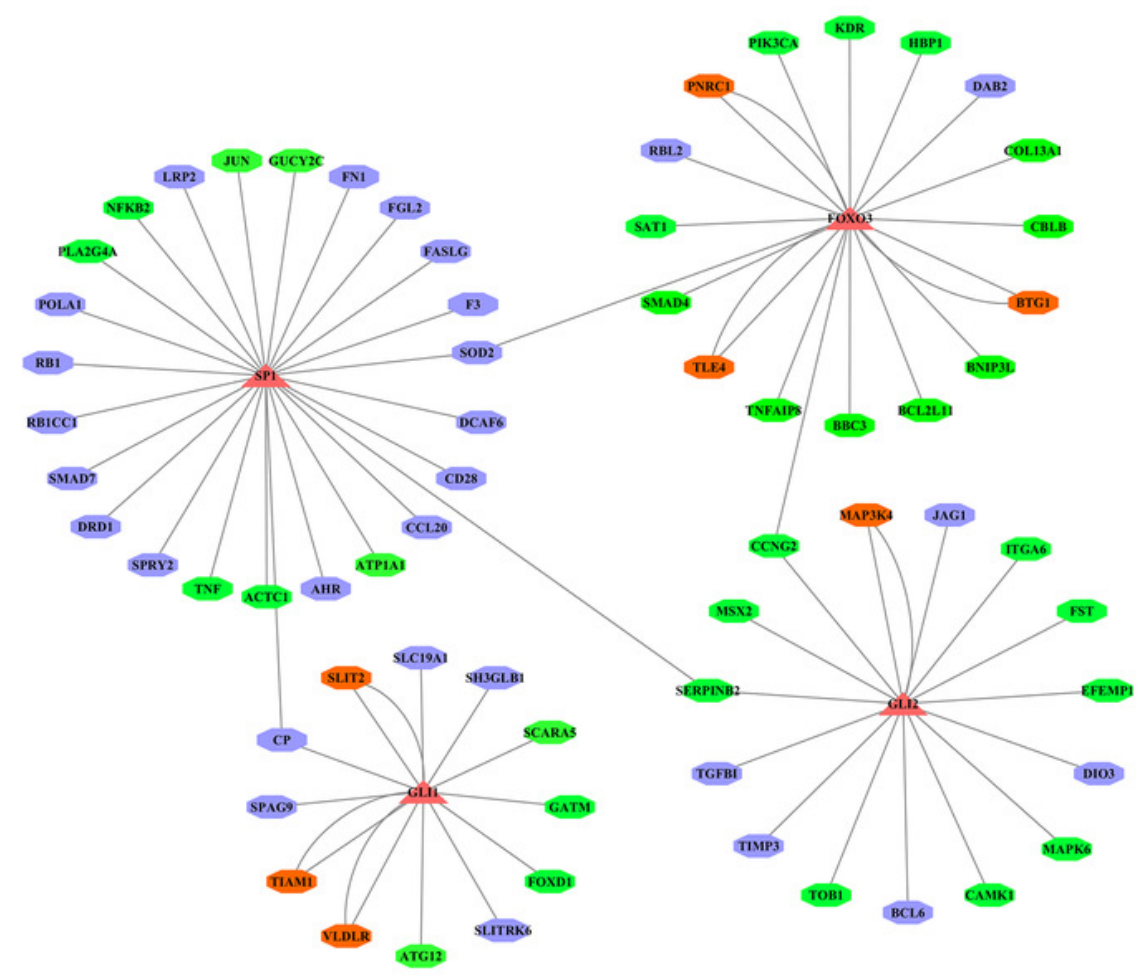
Figure 6

Figure 6. A miR-3568-biological processes-gene network.

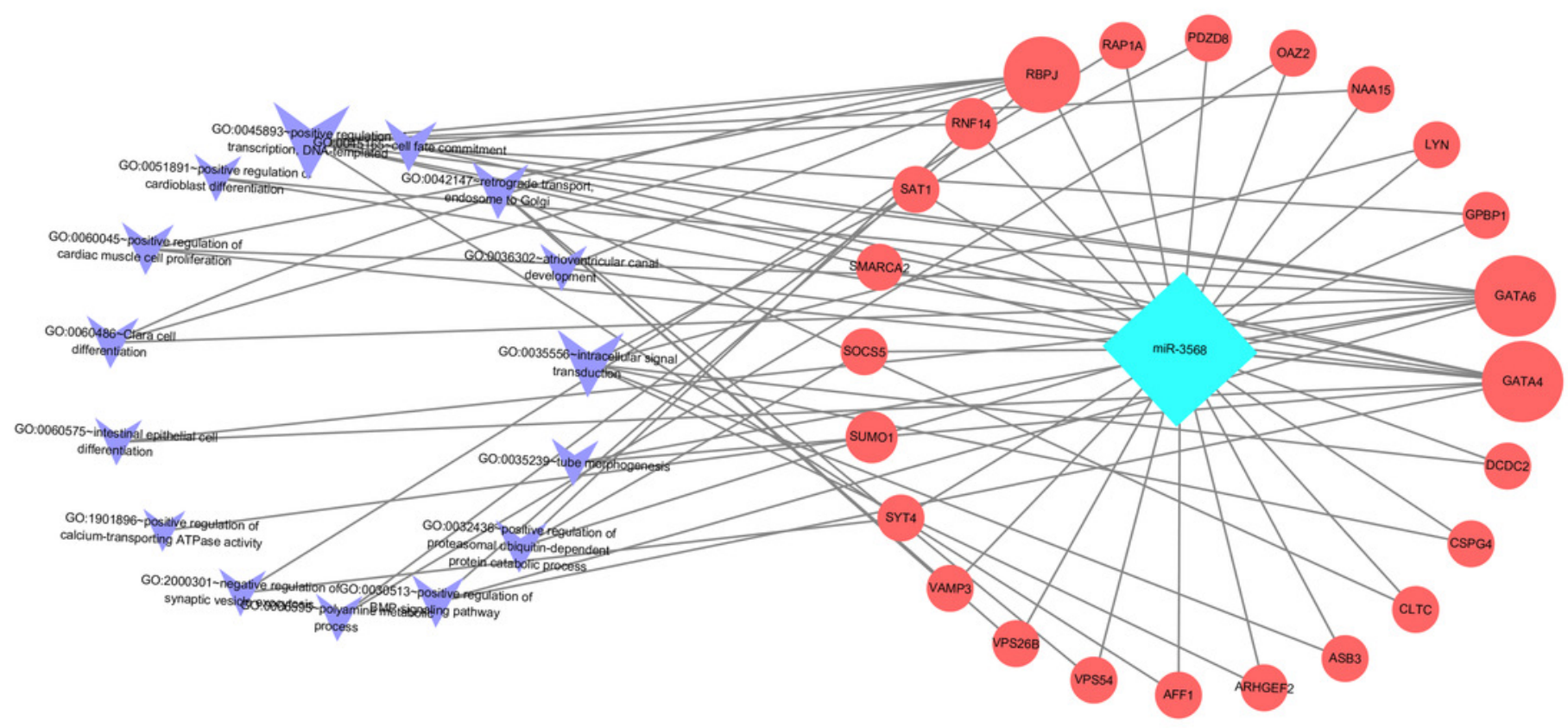


Figure 7

Figure 7. Effects of AMO-3568 following SCII.

Effects of AMO-3568 following SCII. (A) Tarlov scores. $n=8$ for per group. (B-E) The protein expression levels of cleaved caspase-3, Bax, and Bcl-2 were measured with Western blot assay. $n=4$ for per group. Data were analyzed with the one-way ANOVA followed by the Tukey's test. ${ }^{*} p<0.05$, versus the sham group, ${ }^{*} p<0.05$ versus the SCIl group.

A

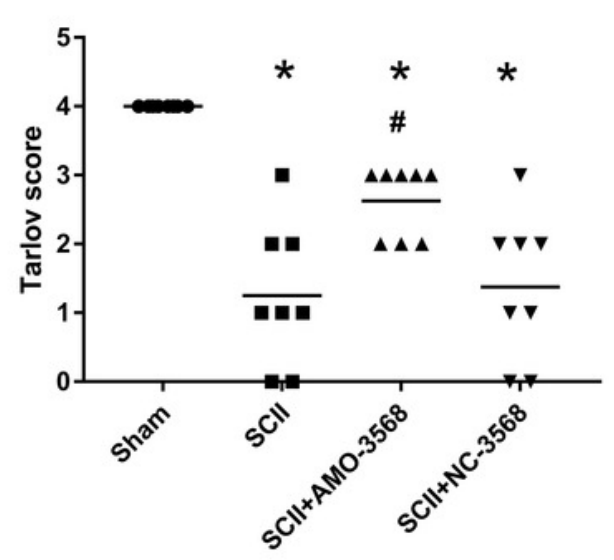

C

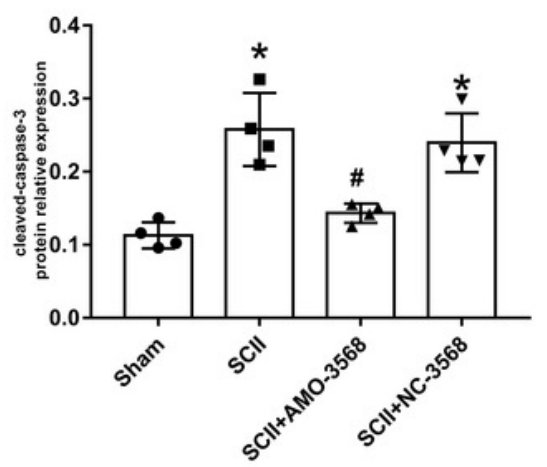

B

cleaved-caspase-3

Bax

$\mathrm{Bcl}-2$

GAPDH

D

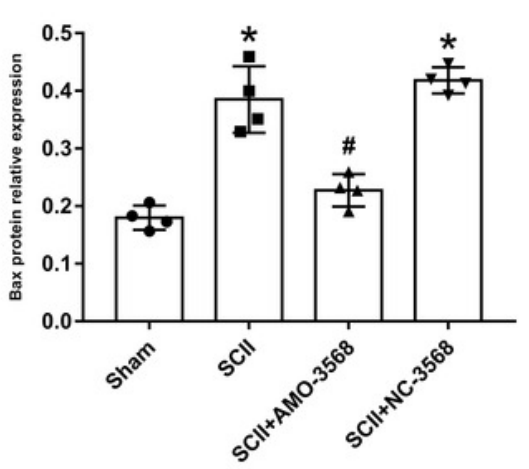


Figure 8

Figure 8. Effects of AMO-3568 on the protein expression levels of RPBJ (A, B), GATA6(A, C) and GATA4(A, D) were measured by Western blot assay.

Effects of AMO-3568 on the protein expression levels of RPBJ (A, B), GATA6(A, C) and GATA4(A, D) were measured by Western blot assay. $n=4$ for per group. Data were analyzed by one-way ANOVA followed by the Tukey's test. ${ }^{*} p<0.05$, versus the sham group, ${ }^{*} p<$ 0.05 versus the SCII group.

A

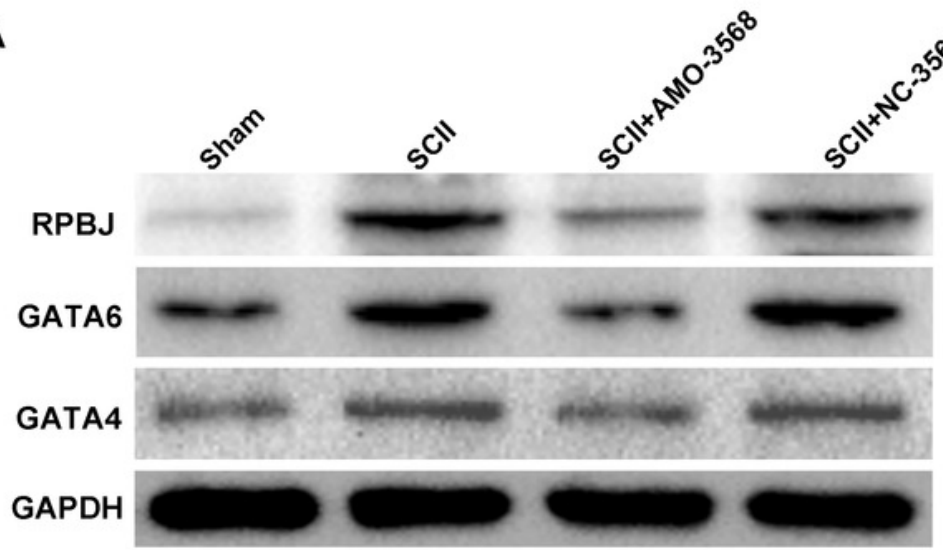

C

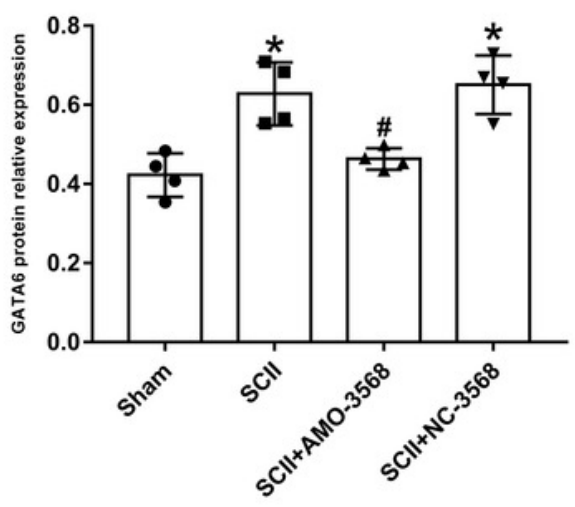

B
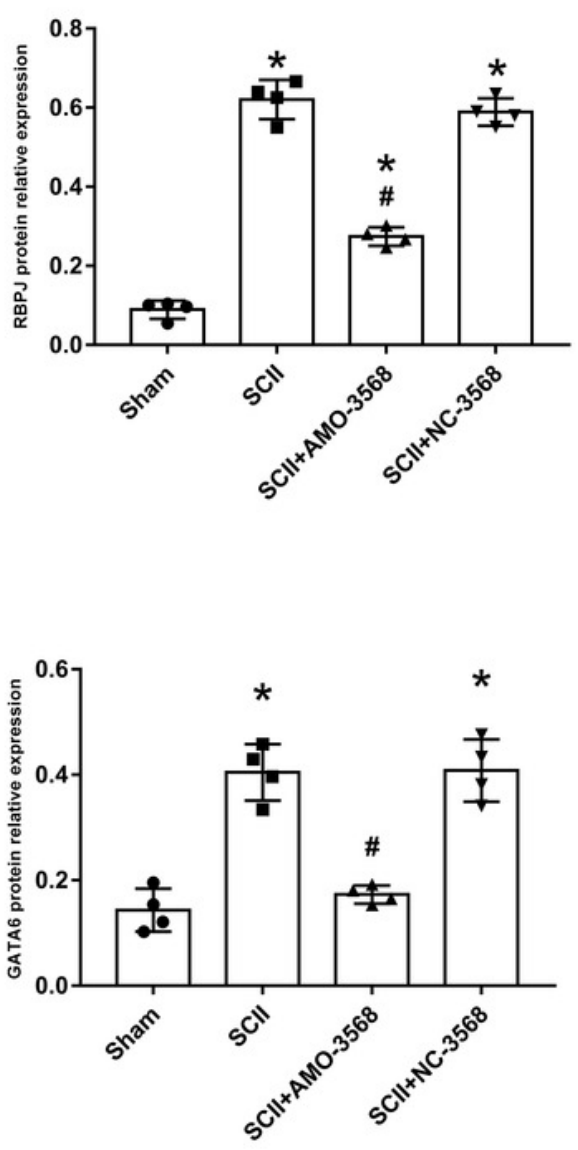